OPEN ACCESS

Cathode Loading Impact on Voltage Cycling Induced PEMFC Degradation: A Voltage Loss Analysis

To cite this article: Gregor S. Harzer et al 2018 J. Electrochem. Soc. 165 F3118

View the article online for updates and enhancements. 


\title{
Cathode Loading Impact on Voltage Cycling Induced PEMFC Degradation: A Voltage Loss Analysis
}

\author{
Gregor S. Harzer, 1 1,=,*,z Jan N. Schwämmlein, ${ }^{1,=, *}$ Ana Marija Damjanović, ${ }^{2}$ \\ Sourov Ghosh, ${ }^{1}$ and Hubert A. Gasteiger ${ }^{1, * *}$ \\ ${ }^{1}$ Chair of Technical Electrochemistry, Department of Chemistry and Catalysis Research Center, Technical University of \\ Munich, D-85748 Garching, Germany \\ ${ }^{2}$ Faculty of Chemical Engineering and Technology, University of Zagreb, 10000 Zagreb, Croatia
}

\begin{abstract}
This study focuses on voltage cycling induced degradation of cathodes with different loading $\left(0.4\right.$ and $\left.0.1 \mathrm{mg}_{\mathrm{Pt}} / \mathrm{cm}^{2}\right)$ when applying square wave or triangular wave based accelerated stress tests (ASTs) between 0.6 and $1.0 \mathrm{~V}_{\mathrm{RHE}}$. The degradation of the $\mathrm{H}_{2} / \mathrm{O}_{2}$ and $\mathrm{H}_{2}$ /air performance upon extended voltage cycling (up to 30000 cycles) was analyzed in terms of the voltage loss contributions from ORR kinetics, $\mathrm{O}_{2}$ mass transport resistances and proton conduction resistances in the cathode. The extent of cathode thinning due to carbon support corrosion was determined by post mortem electrode thickness measurements. Square waves were found to cause a more rapid loss of ECSA and mass activity compared to triangular waves, which was shown to be due to the longer hold periods at high potentials rather than to the rate of the potential transient. The observed increase of the $\mathrm{O}_{2}$ mass transport resistance with voltage cycling was found to mainly depend on the available Pt surface area, while mass transport resistances due to carbon corrosion were found to be insignificant. Finally, it was shown that by lowering the upper potential limit to $0.85 \mathrm{~V}_{\mathrm{RHE}}$, low-loaded catalyst layers can sustain 30000 potential cycles without degradation of the $\mathrm{H}_{2}$ /air performance.

(C) The Author(s) 2018. Published by ECS. This is an open access article distributed under the terms of the Creative Commons Attribution 4.0 License (CC BY, http://creativecommons.org/licenses/by/4.0/), which permits unrestricted reuse of the work in any medium, provided the original work is properly cited. [DOI: 10.1149/2.0161806jes]

(c)) BY
\end{abstract}

Manuscript submitted December 27, 2017; revised manuscript received February 28, 2018. Published March 14, 2018. This paper

is part of the JES Focus Issue on Proton Exchange Membrane Fuel Cell (PEMFC) Durability.

Currently, proton exchange membrane fuel cells (PEMFCs) are on the verge of widespread commercialization as an alternative power source for the automotive market, impressively demonstrated by the launch of PEMFC based vehicles by Toyota, ${ }^{1}$ Hyundai, ${ }^{2}$ and $\mathrm{Honda}^{3}$ in recent years. The major hurdle for a significant market penetration of PEMFC vehicles in the near future is the reduction of system cost and the amount of platinum, while meeting long-term durability targets. ${ }^{4,5}$ Despite remarkable achievements in lowering the Pt loading of the cathode catalyst layer in state-of-the-art membrane electrode assemblies (MEAs) down to $\approx 0.1 \mathrm{mg}_{\mathrm{Pt}} / \mathrm{cm}^{2},{ }^{6-8}$ recent studies have shown that additional overpotentials occur at low loadings and high current density. ${ }^{8-11}$ Even though the exact origin of these losses is subject to ongoing discussions in the literature, its occurrence was directly correlated to the available Pt surface area in the cathode, i.e., to the cathode roughness factor ( $r f$, defined as Pt surface area per geometric surface area in units of $\left.\mathrm{cm}_{\mathrm{Pt}}^{2} / \mathrm{cm}^{2}\right)$, so that it is often referred to as Pt specific $\mathrm{O}_{2}$ mass transport resistance $\left(R_{\mathrm{O}_{2}}^{\mathrm{Pt}}\right){ }^{8-10}$ Additionally, it is well-known that MEAs degrade under the dynamic load-cycles relevant for automotive applications due to the associated voltage cycles. This made extended voltage cycling tests a frequently applied accelerated stress test (AST) to probe the durability of the cathode catalyst layer. Despite various reports in the literature employing different aging protocols, such as applying square wave (SW) potential perturbations or constant high potential phases, the most commonly applied aging protocol is based on triangular wave (TW) potential perturbations between cell voltages of 0.6 and $1.0 \mathrm{~V}$ at a scan rate of typically $50 \mathrm{mV} / \mathrm{s}^{12-21}$

Thermodynamically, the carbon black support for the noble metal catalyst in the MEA is not stable under fuel cell operating conditions, since the equilibrium potential of the carbon oxidation reaction (COR) is only $0.2 \mathrm{~V}_{\mathrm{RHE}}$ (considering $\mathrm{CO}_{2}$ as reaction product). ${ }^{22}$ Fortuitously, the sluggish kinetics of the COR prevent the oxidation of carbon at potentials $<0.9 \mathrm{~V}_{\mathrm{RHE}}$, i.e., within the typical fuel cell operating range, ${ }^{17,23,24}$ and therefore enable its use in the cathode catalyst layer. On the other hand, high voltage periods, occurring for example during

\footnotetext{
$=$ These authors contributed equally to this work.

*Electrochemical Society Student Member.

**Electrochemical Society Fellow.

${ }^{\mathrm{z}}$ E-mail: gregor.harzer@tum.de
}

system start-up or shut-down, can oxidize the carbon structure in the catalyst layer, eventually leading to a loss of void volume and a thinning of the electrode (often referred to as "cathode thinning"). ${ }^{25-27}$ Since a sufficiently large void volume is crucial for the transport of $\mathrm{O}_{2}$ through the cathode catalyst layer, significant corrosion of the carbon support causes an increase of the $\mathrm{O}_{2}$ mass transport resistance and a decrease of PEMFC performance. In addition, carbon corrosion was found to cause a detachment of Pt from the carbon support, leaving the Pt nanoparticles electrically disconnected from the electrode, which decreases the available electrochemical surface area (ECSA) of Pt. Another source of ECSA loss during ASTs are repetitive changes of the cathode potential, leading to oxidation and reduction of the Pt surface. ${ }^{13,14,20}$ Upon its reduction/oxidation, Pt surface atoms can dissolve from the nanoparticle into the electrolyte as ionic species, eventually redepositing on existing Pt nanoparticles via a process referred to as Ostwald ripening, resulting in an increase of the average Pt particle size and an associated ECSA loss. ${ }^{28,29}$ Furthermore, as long as the electrode is held at high potentials, Pt ions can diffuse in the electrolyte phase towards the membrane where they can react with cross-over hydrogen to form electrically insulated Pt deposits within the membrane phase. ${ }^{30}$ Since these Pt deposits can no longer contribute to the electrochemical processes in the cathode catalyst layer, a significant decrease of the ECSA is observed.

To gain a better understanding of the aging processes occurring during voltage cycling ASTs, high-loaded $\left(0.4 \mathrm{mg}_{\mathrm{P}_{\mathrm{t}}} / \mathrm{cm}^{2}\right)$ and lowloaded $\left(0.1 \mathrm{mg}_{\mathrm{Pt}} / \mathrm{cm}^{2}\right)$ MEAs were exposed to different potential cycling profiles: square waves, triangular waves, and triangular waves with an upper and lower potential hold (TW-H). The associated losses of ECSA and ORR mass activity were quantified by cyclic voltammetry and by differential flow $\mathrm{H}_{2} / \mathrm{O}_{2}$ performance measurements, respectively. Furthermore, the performance degradation of differential flow $\mathrm{H}_{2}$ /air polarization curves was analyzed by quantifying the proton conduction resistance via electrochemical impedance spectroscopy (EIS) and by determining the oxygen transport resistance via limiting current diagnostics. The comparison of MEA performance vs ECSA over the course of extended voltage cycling provides insights into the voltage cycling induced increase of the $\mathrm{O}_{2}$ transport resistance. In addition, by deliberately corroding the carbon support through a high-potential hold of the cathode, where substantial carbon corrosion occurs $\left(1.2 \mathrm{~V}_{\text {cell }}\right.$ for $\left.8 \mathrm{~h}\right)$, resulting in pronounced cathode thinning at a 
reasonable ECSA retention, we were able to distinguish between the impact of carbon corrosion and ECSA loss on the limiting current measurements. Comparing the various voltage cycling protocols, it could be shown that the higher degradation observed for square wave compared to triangular wave modulation were due to the extended time at high potentials in the former rather than to the voltage ramp rate between upper and lower potential. Our analysis also showed that the oxygen transport resistances developing over the course of voltage cycling ASTs predominantly depends on the specific current density (in units of $\mathrm{A} / \mathrm{cm}_{\mathrm{Pt}}^{2}$ ), independent of the initial Pt loading of the MEAs.

\section{Experimental}

Comprehensive experimental details on MEA preparation and fuel cell testing are given in our previous publication, ${ }^{11}$ but the most pertinent information is given below. All potentials referred to in cyclic voltammograms and in voltage cycling experiments are referenced to the reversible hydrogen electrode (RHE) potential at a nominal $\mathrm{H}_{2}$ pressure of $100 \mathrm{kPa}_{\mathrm{abs}}\left(\mathrm{V}_{\mathrm{RHE}}\right)$. This was obtained by correcting for the Nernstian shift of the hydrogen anode if the $\mathrm{H}_{2}$ partial pressure was different from $100 \mathrm{kPa}_{\mathrm{abs}}$. For the voltage cycling tests conducted under $\mathrm{H}_{2} / \mathrm{N}_{2}$ (anode/cathode) at $100 \mathrm{kPa}_{\mathrm{abs}}, 80^{\circ} \mathrm{C}, 100 \% \mathrm{RH}$, the different applied potential limits of $0.60,0.85$, and $1.00 \mathrm{~V}_{\mathrm{RHE}}$ correspond to cell voltage limits of $0.59,0.84$, and $0.99 \mathrm{~V}_{\text {cell }}$. If not stated otherwise, area-normalized currents (e.g., $\mathrm{cm}^{2}$ ) refer to the geometric area of the electrode. Furthermore, note that all pressures were measured and controlled at the inlet of the fuel cell and are stated as absolute pressures.

Membrane electrode assembly preparation.-All fuel cell tests were conducted with $5 \mathrm{~cm}^{2}$ MEAs, fabricated by the decal transfer method. Catalyst inks were prepared by mixing the catalyst with a low equivalent weight ionomer in a water-solvent dispersion (Asahi Kasei, 700 EW). To realize the same electrode thickness (identical carbon loading of $0.4 \mathrm{mg}_{\mathrm{C}} / \mathrm{cm}^{2}$ ), two catalysts with different $\mathrm{Pt} / \mathrm{C}$ ratio were used. For low-loaded catalyst layers, a $20 \%_{\text {wt }}$ Pt/Vulcan catalyst (TEC10V20E, Tanaka Kikinzoku Kogyo K.K., TKK) and for high-loaded catalyst layers, a $50 \%_{\mathrm{wt}} \mathrm{Pt} /$ Vulcan (TEC10V50E, TKK) was used. The ink components were added into a $15 \mathrm{~mL}$ capped bottle (HDPE), already containing $16.5 \mathrm{~g}$ of $5 \mathrm{~mm}$ $\mathrm{ZrO}_{2}$ beads as grinding medium in the following sequence: catalyst, water, 1-propanol, and finally the ionomer dispersion. The water concentration of the ink was $10 \%_{\mathrm{wt}}$, while the solid content was $0.03 \mathrm{~g} / \mathrm{mL}_{\text {ink }}$ to obtain a suitable viscosity for the coating process. The ionomer to carbon weight ratio $(\mathrm{I} / \mathrm{C})$ was 0.65 . The inks were mixed by placing the bottles onto a roller-mill $(60 \mathrm{rpm})$ for $18 \mathrm{~h}$ at room temperature. Thereafter, the inks were coated on virgin PTFE using the mayer rod technique with the appropriate bar on a coating machine. The same type of anode was used for all experiments, namely $0.1 \mathrm{mg}_{\mathrm{Pt}} / \mathrm{cm}^{2}$ consisting of $20 \% \mathrm{wt}_{\mathrm{wt}} \mathrm{Pt} / \mathrm{C}$ (TEC10V20E, TKK) with an I/C ratio of 0.65 . The MEAs were assembled by hot pressing a $15 \mu \mathrm{m}$ membrane (Asahi Kasei) placed between the anode and cathode decals at $155^{\circ} \mathrm{C}$ for $3 \mathrm{~min}$ with an applied force of $0.11 \mathrm{kN} / \mathrm{cm}^{2}$. The cathode loadings were $0.1 \mathrm{mg}_{\mathrm{Pt}} / \mathrm{cm}^{2}$ and $0.4 \mathrm{mg}_{\mathrm{Pt}} / \mathrm{cm}^{2}$, with a maximum deviation of $\pm 5 \%$, as determined by weighing the decals before and after the catalyst layer transfer. For each aging procedure, two independent fuel cell measurements were conducted and subsequently averaged with error bars corresponding to the mean absolute deviation.

Fuel cell testing equipment.-Electrochemical measurements were performed on an in-house manufactured, single-cell hardware, using commercial graphite flow fields $(0.5 \mathrm{~mm}$ lands/ channels; manufactured by Poco Graphite according to our design). ${ }^{31}$ Gas diffusion layers (GDLs) were supplied by Freudenberg (H14C7) and the GDL compression was adjusted to $20 \pm 1 \%$ by PTFE coated, incompressible fiberglass gaskets, assembled at a torque of $12 \mathrm{Nm}$ (for details see Simon et al.). ${ }^{32}$ Fuel cell tests were performed on automated test stations (G60, Greenlight Innovation) equipped with a potentio-

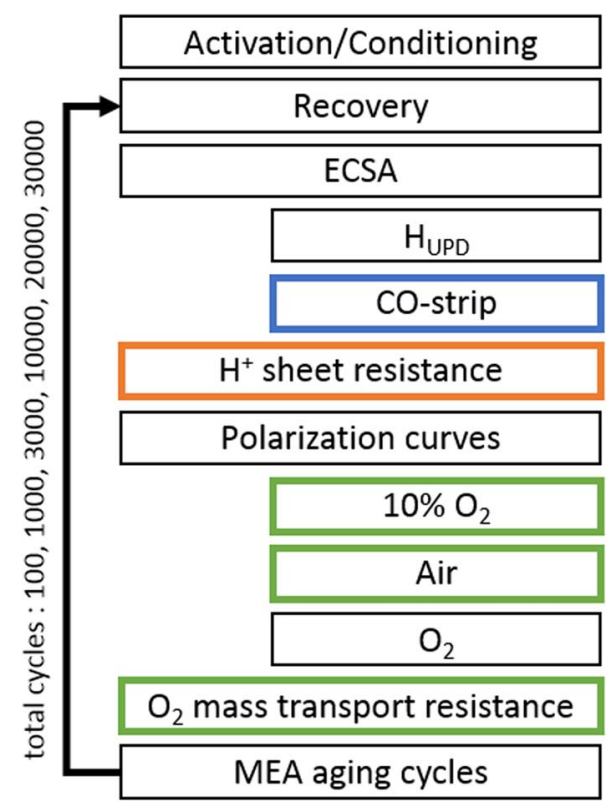

Figure 1. Overview of the experimental procedure for MEA aging. Complete MEA characterization (differential flow $\mathrm{H}_{2} / \mathrm{O}_{2}$ and $\mathrm{H}_{2}$ /air curves, cyclic voltammetry, CO stripping, limiting current measurements, and EIS) was performed at beginning-of-test (BOT) and end-of-test (EOT). The color of the boxes indicates the type of MEA characterization after specific MEA aging cycles: after every aging cycle (black); only at BOT and EOT (orange); after 10000 and 20000 cycles (blue), after 10000 cycles (green)

stat (Reference3000, Gamry) to conduct electrochemical impedance spectroscopy (EIS).

Voltage cycling procedure and diagnostic measurements.-The experimental testing procedure is depicted in Figure 1. All MEAs were conditioned prior to testing, using a voltage-controlled ramp-in procedure $\left(\mathrm{H}_{2}\right.$ /air flows of $1390 / 3320 \mathrm{nccm}$ at $80^{\circ} \mathrm{C}, 100 \%$ relative humidity $(R H)$, and $\left.150 \mathrm{kPa}_{\mathrm{abs}}\right): 0.6 \mathrm{~V}$ for $45 \mathrm{~min}, 5 \mathrm{~min}$ at $\mathrm{OCV}$, and $10 \mathrm{~min}$ at $0.85 \mathrm{~V}$. This sequence was repeated 10 times, after which constant performance was reached. Before each set of differential flow polarization curves and diagnostic measurements, an MEA recovery step was implemented, which consisted of a hold time in $\mathrm{H}_{2}$ /air $(2000 \mathrm{nccm} / 5000 \mathrm{nccm})$ at $0.3 \mathrm{~V}$ for $2 \mathrm{~h}$ at $40^{\circ} \mathrm{C}, 270 \mathrm{kPa}_{\mathrm{abs}}$, and $100 \%$ $R H$. The purpose of this procedure is to recover reversible losses prior to catalyst layer characterization.

Cyclic voltammograms (CVs) of the cathode electrode were recorded between 0.07 and $1.00 \mathrm{~V}_{\mathrm{RHE}}$ at a scan rate of $150 \mathrm{mV} / \mathrm{s}$, at $40^{\circ} \mathrm{C}$ and ambient pressure, while the ECSA was evaluated from $\mathrm{CVs}$ with a limited upper potential of $0.6 \mathrm{~V}_{\mathrm{RHE}}$ by averaging the $\mathrm{H}$-desorption and $\mathrm{H}$-adsorption charge (using a specific charge of $210 \mu \mathrm{C} / \mathrm{cm}_{\mathrm{Pt}_{\mathrm{t}}}^{2}$ ). The counter/reference electrode was fed with $200 \mathrm{nccm}$ of fully humidified $5 \% \mathrm{H}_{2}$ in $\mathrm{N}_{2}$, and the working electrode was initially purged with dry $\mathrm{N}_{2}$ at 50 nccm, while interrupting the gas flow to record the CVs.

$\mathrm{CO}$ stripping was done by adsorbing $\mathrm{CO}\left(10 \% \mathrm{CO}\right.$ in $\mathrm{N}_{2}$, $100 \mathrm{nccm}$ ) for $10 \mathrm{~min}$ at $40^{\circ} \mathrm{C}$ and $150 \mathrm{kPa}_{\mathrm{abs}}$ while maintaining the cathode potential at $0.1 \mathrm{~V}_{\mathrm{RHE}}$. Subsequently, residual $\mathrm{CO}$ was removed from the cell and the gas lines by purging with nitrogen for $\approx 1.5 \mathrm{~h}$. A CV from the holding potential to $1.2 \mathrm{~V}_{\mathrm{RHE}}$ at a scan rate of $100 \mathrm{mV} / \mathrm{s}$ was performed to oxidize the adsorbed CO. Two additional sweeps were recorded to verify the full oxidation and removal of $\mathrm{CO}$ from the electrode and the gas feed system. The ECSA was determined by integrating the area of the first anodic scan with the subsequent sweep as baseline, using a specific charge of $420 \mu \mathrm{C} / \mathrm{cm}_{\mathrm{Pt}}^{2}$.

The proton conduction resistance of the cathode, $R_{\mathrm{H}^{+}}^{\text {cath }}$ (in units of $\Omega \cdot \mathrm{cm}^{2}$ ), was determined from AC impedance spectra recorded in $\mathrm{H}_{2} / \mathrm{N}_{2}$ (anode/cathode) at $0.2 \mathrm{~V}_{\text {cell }}$ with a peak-to-peak perturbation of 
$3.5 \mathrm{mV}$ between $500 \mathrm{kHz}$ and $0.2 \mathrm{~Hz}$ (20 points per decade), according to a procedure reported in the literature, ${ }^{33,34}$ based on a transmission line model. ${ }^{35}$ In order to ensure reproducibility, the measurement was repeated three times at each condition: $100,70,50$, and $30 \% R H$, while maintaining constant gas partial pressures (i.e., at cell pressures of $270,255,246$, and $236 \mathrm{kPa}_{\mathrm{abs}}$, respectively) under differential flow conditions $\left(\mathrm{H}_{2} / \mathrm{N}_{2}\right.$ at $\left.1000 / 1000 \mathrm{nccm}\right)$ at $80^{\circ} \mathrm{C}$. The proton resistivity, $\rho_{\mathrm{H}^{+}}^{\text {cath }}$ (in units of $\Omega \cdot \mathrm{cm}$ ), was calculated by dividing $R_{\mathrm{H}^{+}}^{\text {cath }}$ by the cathode thickness.

Differential flow polarization curves were recorded in currentcontrol mode at $80^{\circ} \mathrm{C}, 170 \mathrm{kPa}_{\text {abs }}$ inlet-controlled pressure, $100 \% \mathrm{RH}$ for both reactants, and constant flows of $2000 \mathrm{nccm}$ of $\mathrm{H}_{2}$ on the anode and 5000 nccm of $\mathrm{O}_{2}$, air, or $10 \% \mathrm{O}_{2}$ (balanced with $\mathrm{N}_{2}$ ) on the cathode. Anode and cathode were operated in counter flow mode. At these conditions, the inlet to outlet pressure drop in anode and cathode was about 2 and $22 \mathrm{kPa}_{\mathrm{abs}}$, respectively. Prior to recording a polarization curve from low to high current densities, the cathode potential was held at $0.75 \mathrm{~V}$ for $15 \mathrm{~min}$ to reduce Pt-oxides; each current density point was held constant for at least $10 \mathrm{~min}$ and the resulting voltage was averaged over the final $30 \mathrm{~s}$. The ORR kinetics (mass activity, specific activity, and Tafel slopes) were determined from $\mathrm{H}_{2} / \mathrm{O}_{2}$ polarization curves after application of two corrections: i) the potential was corrected for the $i R$-drop, using the high frequency resistance $(H F R)$ obtained from the $\mathrm{x}$-axis intersect in the Nyquist plot measured by galvano electrochemical impedance spectroscopy (GEIS) in the frequency range from $100 \mathrm{kHz}$ to $10 \mathrm{~Hz}$ at each current density (applying a 10\% AC amplitude with respect to the current, limited to a minimum/ maximum of $0.1 / 3.0 \mathrm{~A}$ ); ii) the current was corrected for the ohmic short of the membrane, as well as for the $\mathrm{H}_{2}$ crossover, both determined in $\mathrm{H}_{2} / \mathrm{N}_{2}(150 / 600 \mathrm{nccm})$ at $170 \mathrm{kPa}_{\mathrm{abs}}$, $80^{\circ} \mathrm{C}$, and $100 \% \mathrm{RH}$ by applying a constant potential of $0.2,0.3,0.4$, $0.5,0.6$ and $0.7 \mathrm{~V}$ for 2 min each.

The total mass transport resistance $\left(\mathrm{R}_{\mathrm{O}_{2}}^{\text {total }}\right)$ was extracted from limiting current measurements at $80^{\circ} \mathrm{C}$ and $100 \% \mathrm{RH}$ under differential flow conditions ( $2000 \mathrm{nccm}$ of $\mathrm{H}_{2}$ and $5000 \mathrm{nccm}$ of $\mathrm{O}_{2} / \mathrm{N}_{2}$ mixtures). ${ }^{15,36,37}$ The dry mole fraction of oxygen was altered from 4 to $24 \% \mathrm{O}_{2}$ in $\mathrm{N}_{2}$, while the cell potential was set to $0.30,0.15$, 0.10 , and $0.05 \mathrm{~V}$ for $2 \mathrm{~min}$ each. To quantify pressure-independent and pressure-dependent oxygen transport resistances, limiting current measurements were also conducted at $170,270,350$, and $500 \mathrm{kPa}_{\mathrm{abs}}$.

Aging of the cathode electrodes was performed at $100 \mathrm{kPa}_{\mathrm{abs}}, 80^{\circ} \mathrm{C}$, $100 \% \mathrm{RH}$ and $\mathrm{H}_{2} / \mathrm{N}_{2}$ flows of $200 \mathrm{nccm} / 75 \mathrm{nccm}$ on anode/cathode, respectively. In voltage cycling ASTs, various potential profiles were examined that are depicted in Figure 2: triangular wave modulation between a lower potential of $0.6 \mathrm{~V}_{\mathrm{RHE}}$ and an upper potential of either $1.0 \mathrm{~V}_{\mathrm{RHE}}$ (referred to as "TW", a) or a lower upper potential limit of $0.85 \mathrm{~V}_{\mathrm{RHE}}$ (referred to as "TW-LUPL", d) at $50 \mathrm{mV} / \mathrm{s}$; square wave (SW, b) modulation between 0.6 and $1.0 \mathrm{~V}_{\mathrm{RHE}}$; and triangular wave modulation with a potential hold at the lower $\left(0.6 \mathrm{~V}_{\mathrm{RHE}}\right)$ and upper $\left(1.0 \mathrm{~V}_{\mathrm{RHE}}\right)$ potential (referred to as "TW-H", c). Voltage cycling ASTs were controlled by a potentiostat (Reference3000, Gamry). To avoid reductive currents during potential cycling, all residual $\mathrm{O}_{2}$ was removed from the humidifier and gas line system by a $\mathrm{N}_{2}$ purging procedure, lasting about $45 \mathrm{~min}$. The scan rate for all TW procedures was $50 \mathrm{mV} / \mathrm{s}$, while the potential step in the SW procedure was completed in less than 0.1 seconds (corresponding to an average rate of $>4 \mathrm{~V} / \mathrm{s}$ ). The hold times of $8 \mathrm{~s}$ at the vertex potentials in the SW procedure was chosen such that it is identical to the overall time required for one TW cycle (compare Figures $2 \mathrm{a}$ and $2 \mathrm{~b}$ ).

Electrode thickness determination by SEM.-The thicknesses of pristine (BOT), as well as aged MEAs (EOT) were determined from cross-section images, obtained by scanning electron microscopy (SEM). To get a more accurate comparison between BOT/EOT and to exclude any effects of cell assembly on the catalyst layer thickness, the pristine MEAs were assembled in a cell and operated at $80^{\circ} \mathrm{C}, 100 \% \mathrm{RH}$ and $500 \mathrm{nccm} \mathrm{N}_{2} / \mathrm{N}_{2}$ flows at ambient pressure for $24 \mathrm{~h}$ before determining their initial thickness. The MEAs were cut in quarters, using one quarter close to the gas inlet and one close to

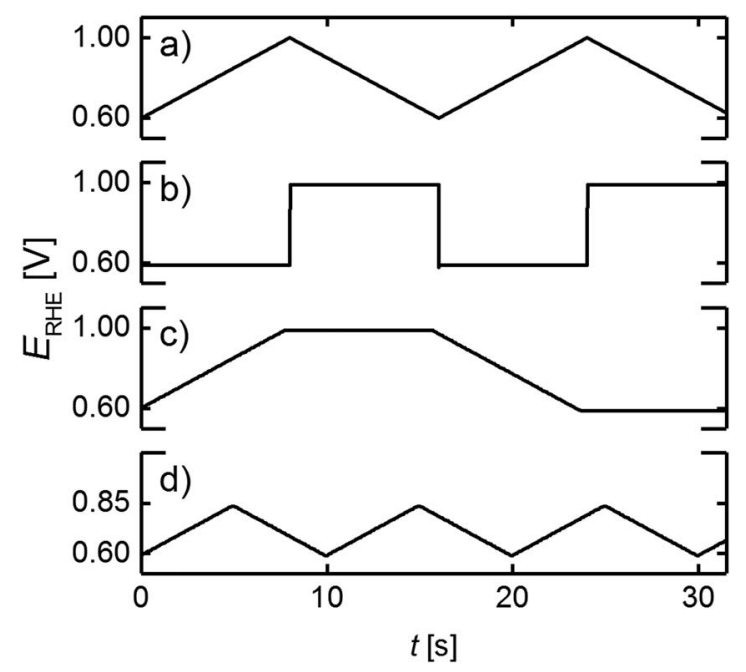

Figure 2. Voltage profiles used in voltage cycling ASTs performed at $100 \mathrm{kPa}_{\mathrm{abs}}, 80^{\circ} \mathrm{C}, 100 \% \mathrm{RH}$ and $\mathrm{H}_{2} / \mathrm{N}_{2}$ flows of $200 \mathrm{nccm} / 75 \mathrm{nccm}$ on anode/cathode, respectively. a) triangular wave modulation ("TW") between 0.6 and $1.0 \mathrm{~V}_{\mathrm{RHE}}$ (corresponding to 0.59 and $0.99 \mathrm{~V}_{\text {cell }}$ ) at a scan rate of $50 \mathrm{mV} / \mathrm{s}$; b) square wave modulation ("SW"), applying a hold time of $8 \mathrm{~s}$ at the lower $\left(0.6 \mathrm{~V}_{\mathrm{RHE}}\right)$ and upper $\left(1.0 \mathrm{~V}_{\mathrm{RHE}}\right)$ potential; c) triangular wave modulation at a scan rate of $50 \mathrm{mV} / \mathrm{s}$ with $8 \mathrm{~s}$ potential hold at the lower $\left(0.6 \mathrm{~V}_{\mathrm{RHE}}\right)$ and upper (1.0 $\left.\mathrm{V}_{\mathrm{RHE}}\right)$ limits ("TW-H"); d) triangular wave modulation at 50 $\mathrm{mV} / \mathrm{s}$ between $0.6 \mathrm{~V}_{\mathrm{RHE}}$ and a lowered upper potential limit ("TW-LUPL") of $0.85 \mathrm{~V}_{\mathrm{RHE}}\left(\equiv 0.84 \mathrm{~V}_{\text {cell }}\right)$. The combination of an anodic and a cathodic scan is referred to as one cycle in this study.

outlet of the cell. The samples were fixed in a Teflon holder and embedded in epoxy resin (EpoThin 2 resin and hardener, Buehler Ltd.) at reduced pressure to remove gas bubbles. After hardening overnight at $40^{\circ} \mathrm{C}$, the resin block was removed from the holder, ground on $\mathrm{SiC}$ (CarbiMet S, P280, Buehler Ltd.) under constant water flow and thoroughly cleaned by ultrasonification in water. SEM (JCM-6000PLUS NeoScope, Jeol) images were taken in backscattering mode at $15 \mathrm{kV}$ accelerating voltage and a magnification of $2000 \mathrm{x}$ at ten arbitrarily chosen locations for each quarter of an MEA, generating 20 images per MEA. The thickness of the electrode was determined by integration of the electrode area with ImageJ (version 1.51j8) and dividing by the length of the image as shown in Figure 3. This way, the entire image is evaluated, which provides a more accurate measure of the catalyst layer thickness compared to a single point measurement.

The thickness of pristine electrodes was used to calculate the packing density of the Vulcan carbon based electrodes. The obtained packing density of $22 \pm 4 \mu \mathrm{m} /\left(\mathrm{mg}_{\mathrm{C}} / \mathrm{cm}^{2}\right)$ is in reasonable agreement with values in the literature. ${ }^{38}$ The BOT thickness for all tested MEAs was

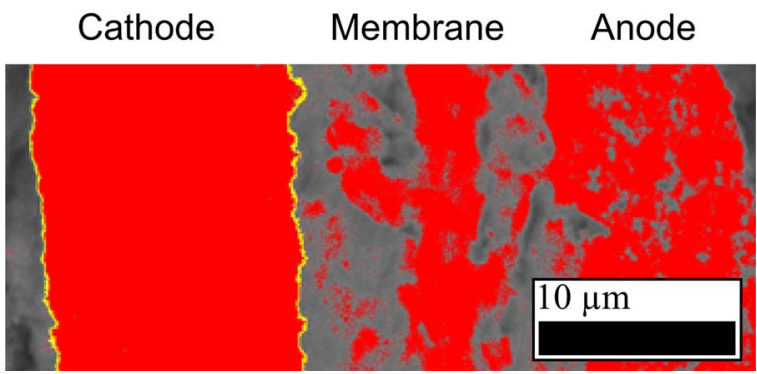

Figure 3. Cross-sectional SEM image of an MEA embedded in epoxy resin and taken at an acceleration voltage of $15 \mathrm{kV}$ and a magnification of 2000x. The cathode edges are marked in yellow and the integrated area in between is shown in red, based on the grayscale of the image. Red areas outside the cathode are not included in the evaluation. 
calculated from the transferred weight of carbon in the hot pressing process and the packing density.

\section{Results and Discussion}

In this study, we present the aging behavior of MEAs exposed to different voltage cycling protocols, with the respective voltage transients shown in Figure 2. The most commonly used AST is a potential scan between 0.6 and $1.0 \mathrm{~V}_{\mathrm{RHE}}$ at a scan rate of $50 \mathrm{mV} / \mathrm{s}$ and $80^{\circ} \mathrm{C}$ in inert gas atmosphere, termed TW in this manuscript (Figure 2a). In addition, many researchers reported the aging behavior of MEAs exposed to square wave (SW) voltammetry (Figure $2 b$ ), since the combination of fast potential transients and hold periods has proven to accelerate catalyst layer degradation. ${ }^{39,40}$ However, it is not wellunderstood yet, whether the holding time at the respective potential or the fast transient from one to the other potential is the dominating factor for the observed electrode degradation. To deconvolute between TW and SW modulations, triangular scans were combined with a potential hold period (TW-H) in order to eliminate the fast potential step while maintaining the effect of the hold time (Figure 2c). Furthermore, electrode aging by a TW modulation between 0.6 and $1.0 \mathrm{~V}_{\mathrm{RHE}}$ will be compared to a TW modulation with the same lower voltage limit but with a lowered upper potential limit of $0.85 \mathrm{~V}_{\mathrm{RHE}}$ (TW-LUPL), where carbon support corrosion can safely be assumed to be negligible and where Pt dissolution rates are expected to be reduced (Figure 2d). Finally, our study is complemented by a potential hold experiment at $1.2 \mathrm{~V}_{\text {cell }}$ for $8 \mathrm{~h}$ (under $\mathrm{N}_{2}$ at $95^{\circ} \mathrm{C}, 100 \% \mathrm{RH}$, and $100 \mathrm{kPa}_{\mathrm{abs}}$ ) to degrade the carbon support structure via COR, while maintaining a reasonably high electrode roughness factor. All of the aging procedures were conducted on high-loaded $\left(0.4 \mathrm{mg}_{\mathrm{Pt}} / \mathrm{cm}^{2}\right)$ and low-loaded cathodes $\left(0.1 \mathrm{mg}_{\mathrm{Pt}} / \mathrm{cm}^{2}\right)$ to identify similarities and/or differences in the aging behavior with respect to the ECSA and mass activity originating from different catalyst layer loadings. Moreover, changes of the cathode $\mathrm{O}_{2}$ mass transport resistance upon aging, especially with respect to the local $\mathrm{O}_{2}$ mass transport resistance which is commonly observed to be a function of the electrode $r f$ was of major interest in this study. ${ }^{9,10,41}$ The utilization of high- and low-loaded catalyst layers enables a comparison over a wide range of $r f$, i.e., to compare low $\mathrm{Pt}$ specific current densities $\left(\mathrm{A} / \mathrm{cm}_{\mathrm{Pt}}^{2}\right)$ for high-loaded MEAs (high $r f$ ) to high specific current densities after aging of low-loaded cathodes (low $r f$ ). However, to establish a valid comparison of the total mass transport resistance, the same catalyst layer thickness was maintained $(\approx 10 \mu \mathrm{m})$ for all MEAs at BOT by utilizing a $50 \%_{\mathrm{wt}} \mathrm{Pt} / \mathrm{C}$ catalyst for high-loaded and a $20 \%_{\mathrm{wt}} \mathrm{Pt} / \mathrm{C}$ catalyst for low-loaded electrodes.

ECSA evaluation: $\boldsymbol{H}_{U P D}$ vs CO stripping.-To evaluate the degradation of the Pt surface area over the course of MEA aging, CVs were recorded after each aging stage, exemplarily shown in Figure 4a for a single low-loaded MEA $\left(0.1 \mathrm{mg}_{\mathrm{Pt}} / \mathrm{cm}^{2}\right)$ exposed to SW aging between 0.6 and $1.0 \mathrm{~V}_{\mathrm{RHE}}$ (see Figure $2 \mathrm{~b}$ ). To determine the ECSA by integration of the $\mathrm{H}_{\mathrm{UPD}}$ charge, additional CVs with a limited upper potential $\left(0.6 \mathrm{~V}_{\mathrm{RHE}}\right)$ were recorded (not shown) to avoid a contribution of charge originating from the reduction of the Pt surface. ${ }^{42}$ Due to the above outlined Pt dissolution/redistribution mechanisms, the $\mathrm{H}_{\mathrm{UPD}}$ features of the $\mathrm{CV}$ degrade significantly, i.e., a decrease of the cathode $r f$ is observed over the course of extended voltage cycling. In general, the evaluation of the ECSA via integration of the pseudo-capacitive $\mathrm{H}_{\mathrm{UPD}}$ current is influenced by a superimposed faradaic current at low potentials, originating from the hydrogen evolution reaction (HER). This superposition is especially dominant at low $r f$, as the rate of the HER above $0 \mathrm{~V}_{\text {RHE }}$ in cyclic voltammetry is mostly thermodynamically controlled (i.e., it does not depend significantly on the active Pt surface area), whereas the pseudo-capacitive $\mathrm{H}_{\text {UPD }}$ charge scales directly with the available Pt surface area. Hence, the strong decrease of the $r f$ in the course of the voltage cycling AST renders the determination of the ECSA via the $\mathrm{H}_{\mathrm{UPD}}$ method increasingly erroneous, requiring the implementation of $\mathrm{CO}$ stripping to reliably determine the remaining Pt surface area for very low $r f$ values, ${ }^{43}$ i.e., towards the end of the aging protocol.

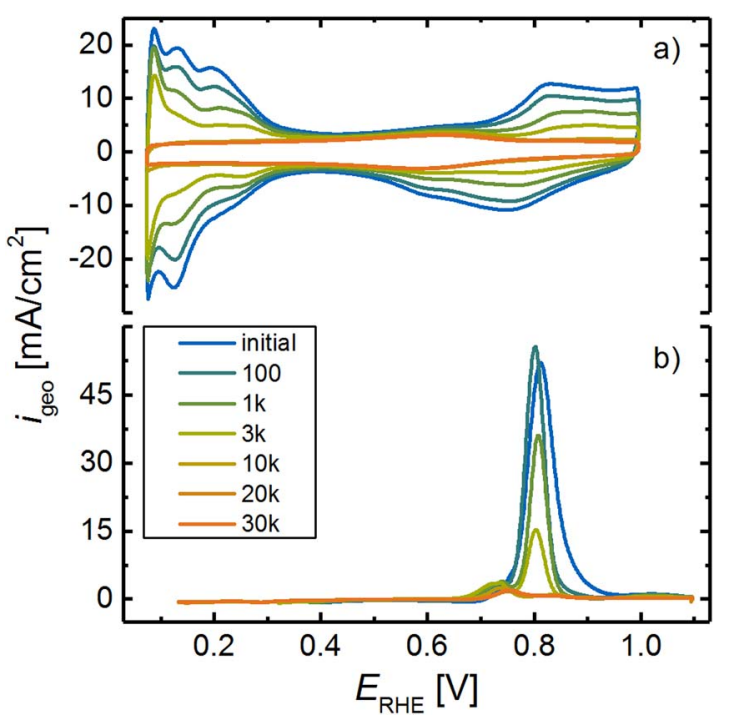

Figure 4. a) CVs of the cathode after different aging stages during a SWbased AST between 0.6 and $1.0 \mathrm{~V}_{\mathrm{RHE}}$ (see Figure 2b). CVs were conducted at a scan rate of $150 \mathrm{mV} / \mathrm{s}$ from 0.07 to $1.00 \mathrm{~V}_{\mathrm{RHE}}$ at ambient pressure and $40^{\circ} \mathrm{C}$ (the anode was supplied with $200 \mathrm{nccm}$ of $5 \% \mathrm{H}_{2}$ (in $\mathrm{N}_{2}$ ) and the cathode $\mathrm{N}_{2}$ flow was $50 \mathrm{nccm}$ (set to zero flow when recording the $\mathrm{CVs}$ )). b) CO stripping voltammograms after subtraction of the subsequent anodic sweep, recorded at a scan rate of $100 \mathrm{mV} / \mathrm{s}$ to $1.1 \mathrm{~V}_{\mathrm{RHE}}$ at $150 \mathrm{kPa}_{\mathrm{abs}}$ and $40^{\circ} \mathrm{C}$ (constant flows of $200 \mathrm{nccm} 5 \% \mathrm{H}_{2}$ on the anode and $5 \mathrm{nccm} \mathrm{N} 2$ on the cathode). $\mathrm{CO}$ was adsorbed for $10 \mathrm{~min}$ at a flow rate of $100 \mathrm{nccm}$ prior to the $\mathrm{CV}$, maintaining the potential at $0.1 \mathrm{~V}_{\mathrm{RHE}}$. To remove residual $\mathrm{CO}$ gas from the cell and the test station, a purging procedure with $\mathrm{N}_{2}$, lasting approximately $1.5 \mathrm{~h}$ was executed.

Representative $\mathrm{CO}$ stripping measurements are shown in Figure $4 \mathrm{~b}$ after subtraction of the second anodic scan. The peak for $\mathrm{CO}$ oxidation occurs at $\approx 0.81 \mathrm{~V}_{\mathrm{RHE}}$, which is consistent with reports by other researchers for $\mathrm{CO}$ oxidation on Pt nanoparticles, ${ }^{44}$ mainly dominated by $\mathrm{CO}$ oxidation on $\mathrm{Pt}(111)$ facets. ${ }^{45,46}$ Furthermore, a second peak at $\approx 0.74 \mathrm{~V}_{\mathrm{RHE}}$ is observed, representing Pt(110)-like planes. ${ }^{47}$ Since those facets are less prone to dissolution upon surface oxidation/reduction, this peak becomes more dominant upon potential cycling. Consistent with the decrease in $\mathrm{H}_{\mathrm{UPD}}$ features, the charge associated with the oxidation of $\mathrm{CO}_{\text {ads }}$ decreases significantly during cathode aging. Since ECSA determination via $\mathrm{H}_{U P D}$ is reasonably accurate for high $r f$ values, the charge ratio between $\mathrm{H}_{\text {UPD }}$ and $\mathrm{CO}$ stripping remains constant $\left(\frac{\mathrm{ECSA}_{\mathrm{H}_{\mathrm{UPD}}}}{\mathrm{ECSA}_{\mathrm{CO}}} \approx 0.8\right)$ throughout the first phase of aging (up to $\approx 3000$ cycles). As the $\mathrm{H}_{\mathrm{ad}}$ formation is not quantitative in the applied potential range $\left(\geq 0.07 \mathrm{~V}_{\mathrm{RHE}}\right)$, the ECSA determined by the $\mathrm{H}_{\text {UPD }}$ method is slightly underestimated compared to the ECSA determined from CO stripping, hence their ratio is below unity. ${ }^{48}$ In the course of potential cycling, the ratio decreases significantly $\left(\frac{E^{E C S A_{U P D}}}{E_{\text {CSA }}}<0.1\right.$ after 10000 cycles $)$, as the electrode $r f$ approaches very low values where the $\mathrm{H}_{\text {UPD }}$ currents are small compared to the capacitive current contributions from the carbon support. As CO stripping was only implemented for electrodes with a considerably low $r f$, and $\mathrm{H}_{\mathrm{UPD}}$ was the preferred method for ECSA determination (due to its experimental simplicity), comparability of these two techniques was assured by introducing a scaling factor. The scaling factor was calculated as the ratio of ECSA determined by $\mathrm{H}_{\mathrm{UPD}}$ and $\mathrm{CO}$ stripping at BOT and was used to correct the values determined by CO stripping to an "H $\mathrm{HPD}_{\mathrm{UPD}}$-derived" ECSA at low $r f$ (denoted by open symbols in figures showing ECSA data in this manuscript).

ECSA evolution during voltage cycling ASTs.-A decrease of the ECSA with increasing number of voltage cycles for each cathode loading and aging protocol is given in Figure 5, eventually reaching similarly low ECSA values on the order of 5-10 $\mathrm{m}_{\mathrm{Pt}}^{2} / \mathrm{g}$ after 


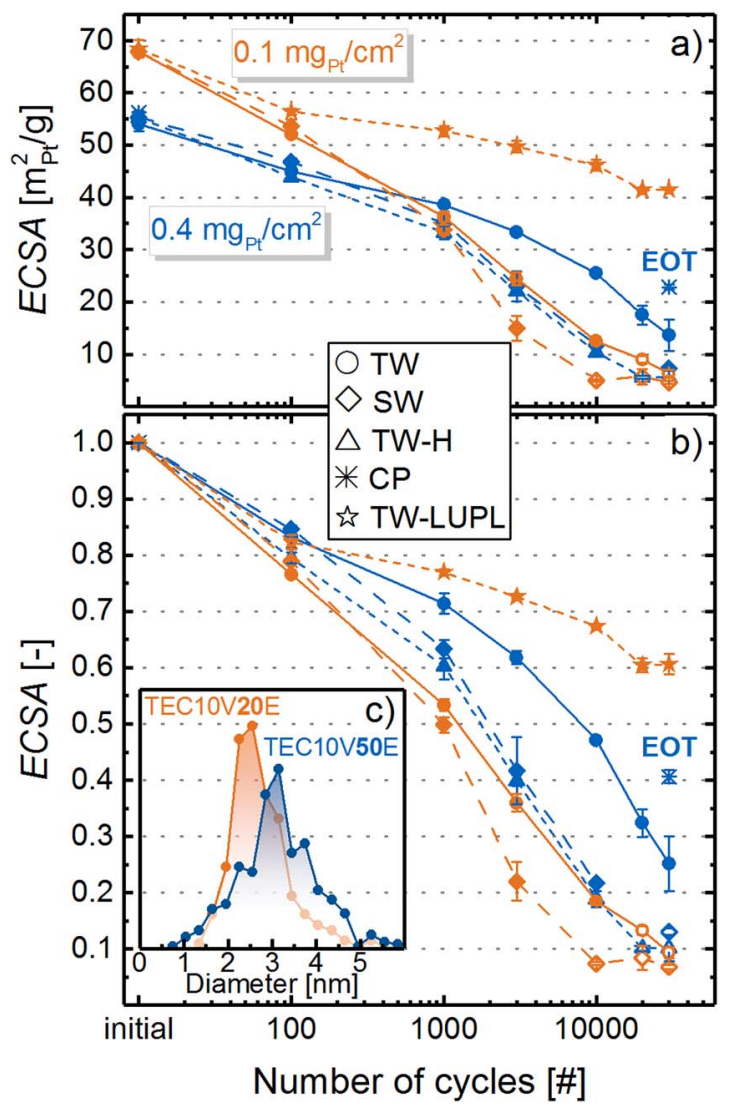

Figure 5. a) Cathode ECSA of all tested MEAs with cathode loadings of $0.4 \mathrm{mg}_{\mathrm{Pt}} / \mathrm{cm}^{2}$ (blue symbols) and $0.1 \mathrm{mg} \mathrm{gt}_{\mathrm{Pt}} / \mathrm{cm}^{2}$ (orange symbols), recorded for TW cycling between 0.6 and $1.0 \mathrm{~V}_{\mathrm{RHE}}$ (s. Figure 2a; solid lines, circles) as well as SW cycling between 0.6 and $1.0 \mathrm{~V}_{\mathrm{RHE}}$ (s. Figure 2b; long-dashed lines, diamonds). For $0.4 \mathrm{mg}_{\mathrm{Pt}} / \mathrm{cm}^{2}$ loadings, also a TW-H profile (s. Figure 2c; short-dashed lines, triangles) was examined, while for $0.1 \mathrm{mg}_{\mathrm{Pt}} / \mathrm{cm}^{2}$ loadings a triangular cycle with a lowered upper potential limit of $0.85 \mathrm{~V}_{\mathrm{RHE}}$ (s. Figure 2d; short-dashed lines, stars) was tested. The single point labeled CP (blue star symbol placed at 30000 cycles) depicts the ECSA after an 8 hour hold at $1.2 \mathrm{~V}_{\text {cell }}$, (under $\mathrm{N}_{2}$ at $95^{\circ} \mathrm{C}, 100 \% R H$, and $100 \mathrm{kPa}_{\mathrm{abs}}$ ), where substantial carbon support oxidation occurs. For high $r f$ values, the ECSA was evaluated from the integration of the $\mathrm{H}_{\text {upd }}$ area, shown by a full symbol in the graph; for low $r f$ values, the ECSA was determined by CO stripping and corrected by the scaling factor to allow comparability with the ECSA determined from $\mathrm{H}_{\text {UPD }}$ (denoted by open symbols). b) ECSA evolution over voltage cycling normalized to its initial value. The error bars represent the mean absolute deviation between two independently conducted experiments for each AST. c) Particle size distribution for the $20 \% \mathrm{wt} \mathrm{Pt} / \mathrm{C}$ catalyst (orange) and the $50 \% \mathrm{wt}$ $\mathrm{Pt} / \mathrm{C}$ catalyst (blue).

30000 cycles (apart from the TW-LUPL and CP protocols). Since the change of potential in the applied ASTs results in a repetitive reduction/oxidation of the Pt surface, Ostwald ripening and a loss of $\mathrm{Pt}$ into the ionomer phase are expected to be the major contributors to the overall loss of active surface area. The gradual stabilization of the ECSA after extended voltage cycling, also observed in previous studies, ${ }^{49}$ is likely due to the higher thermodynamic stability of larger Pt particles against dissolution. In contrast to the similar trend of decaying ECSA for all tested samples, its evolution with respect to the aging protocol and the cathode loading differs widely. First of all, it is noteworthy that the ECSA at BOT is higher for low-loaded cathodes $\left(68 \pm 1 \mathrm{~m}_{\mathrm{Pt}}^{2} / \mathrm{g}\right)$ compared to those with a higher loading $\left(55 \pm 1 \mathrm{~m}_{\mathrm{Pt}}^{2} / \mathrm{g}\right)$. As mentioned earlier, the electrode thickness was maintained constant for all tested MEAs $(\approx 10 \mu \mathrm{m})$, which required a catalyst with $20 \%{ }_{\mathrm{wt}}$ $\mathrm{Pt}$ content to prepare low-loaded catalyst layers, whereas $50 \%_{\mathrm{wt}} \mathrm{Pt} / \mathrm{C}$ was used for high-loaded electrodes. Even though both catalysts were obtained from the same supplier, Pt nanoparticles are commonly more homogeneously dispersed on the carbon support at low Pt to carbon ratio. This leads to a lower degree of Pt agglomeration, hence a lower average particle size and higher $E C S A .{ }^{50}$ In fact, an evaluation of the particle size distribution (Figure $5 \mathrm{c}$ ) by counting $\approx 400$ individual particles (in TEM images) revealed a number averaged diameter of $2.8 \pm 0.8 \mathrm{~nm}$ and $3.2 \pm 1.0 \mathrm{~nm}$ for $20 \%_{\mathrm{wt}}$ and $50 \%_{\mathrm{wt}} \mathrm{Pt} / \mathrm{C}$, respectively. As reported frequently by other researchers, Ostwald ripening is more pronounced for small particles compared to larger ones due to their intrinsically lower stability versus dissolution upon oxidation/ reduction. ${ }^{19}$ In accordance with this, for any given aging protocol, a faster decay of the ECSA is observed for low-loaded (orange colored in Figure 5) compared to high-loaded cathodes (blue colored in Figure 5). In summary, the observed relatively stronger ECSA fade for lower catalyst layer loadings in this study is not primarily caused by the cathode loading itself, but is most likely due to the different aging behavior of $\mathrm{Pt}$ nanoparticles with different size and different degrees of agglomeration.

Comparing different aging protocols, the ECSA loss is more pronounced for MEAs subjected to SW aging (long-dashed lines) compared to TW aging (solid lines), resulting in a dramatically low ECSA already after 10000 square wave cycles between 0.6 and $1.0 \mathrm{~V}_{\mathrm{RHE}}$ $\left(11 \mathrm{~m}_{\mathrm{Pt}}^{2} / \mathrm{g}\right.$ for high-loaded and $5 \mathrm{~m}_{\mathrm{Pt}}^{2} / \mathrm{g}$ for low-loaded cathodes). The accelerated degradation caused by square wave compared to triangular wave aging has frequently been observed for PEMFCs,${ }^{40}$ as well as in liquid electrolyte. ${ }^{39}$ There are four possible hypotheses to rationalize the faster degradation during SW cycling: i) a more significant carbon corrosion due to an extended hold period at high potential, eventually resulting in Pt particle detachment, accompanied by a thinning of the cathode catalyst layer; ii) the fast potential transient of the square wave modulation $(>4 \mathrm{~V} / \mathrm{s}$ ) could induce more severe Pt dissolution forced by a fast reconstruction of the Pt surface from an oxidized to a reduced state; iii) the holding time at high potential induces a growth of the oxide, resulting in a stronger dissolution in the subsequent cathodic scan $;{ }^{51}$ or, iv) the hold time at high anodic potentials provides more time for Pt dissolution and diffusion through the ionomer phase. As was shown by Cherevko et al., polycrystalline $\mathrm{Pt}$ in $0.1 \mathrm{M} \mathrm{H}_{2} \mathrm{SO}_{4}$ dissolves at constant anodic potential during about $600 \mathrm{~s}$ which is in the same order of magnitude as the dissolution during a potential transient. ${ }^{52}$ The constantly released $\mathrm{Pt}$ ions can diffuse towards the membrane, where they are reduced by $\mathrm{H}_{2}$ permeating through the membrane from the anode, causing a redeposition of electrically disconnected Pt particles within the ionomer phase. ${ }^{20}$ The following analysis will shed some light onto the origin of the different aging of MEAs exposed to SW or TW potential profiles as well as at the degradation caused by holding at high potential to deliberately corrode the carbon support.

To investigate whether significant carbon support corrosion takes place over the course of the various voltage cycling protocols, which should lead to cathode thinning, MEA cross sections were prepared at EOT and imaged by SEM. Since the initial thickness of the electrodes at BOT could not be determined by SEM without damaging the MEA, the packing density of high-loaded and low-loaded catalyst layers was evaluated by measuring the thickness and catalyst loading of pristine MEAs (amounting to $22 \pm$ $4 \mu \mathrm{m} /\left(\mathrm{mg}_{\mathrm{C}} / \mathrm{cm}^{2}\right)$, see experimental section), from which the initial thickness of each MEA could be calculated by its measured catalyst weight. The catalyst layers exposed to TW or SW aging between 0.6 and $1.0 \mathrm{~V}_{\mathrm{RHE}}$ (Figures 6a/6b/6d/6e) show no catalyst layer collapse compared to a pristine MEA (Figure 6c), eliminating carbon corrosion as a likely contributor to the overall degradation. Interestingly, the catalyst layers depicted in Figures $6 \mathrm{a} / 6 \mathrm{~b}$ and $6 \mathrm{~d} / 6 \mathrm{e}$ show a bright area at the cathode/membrane interface, representing an accumulation of $\mathrm{Pt}$ in the membrane phase, caused by precipitation of dissolved $\mathrm{Pt}$ in the ionomer phase. ${ }^{20,30}$ However, due to the rather qualitative nature of such SEM images, no conclusion on the quantitative differences between the amount of deposited Pt during TW and SW cycling can be drawn, even though the larger ECSA loss in the SW protocol points towards a higher amount of disconnected $\mathrm{Pt}$. The absence of cathode thinning was also confirmed for all other 

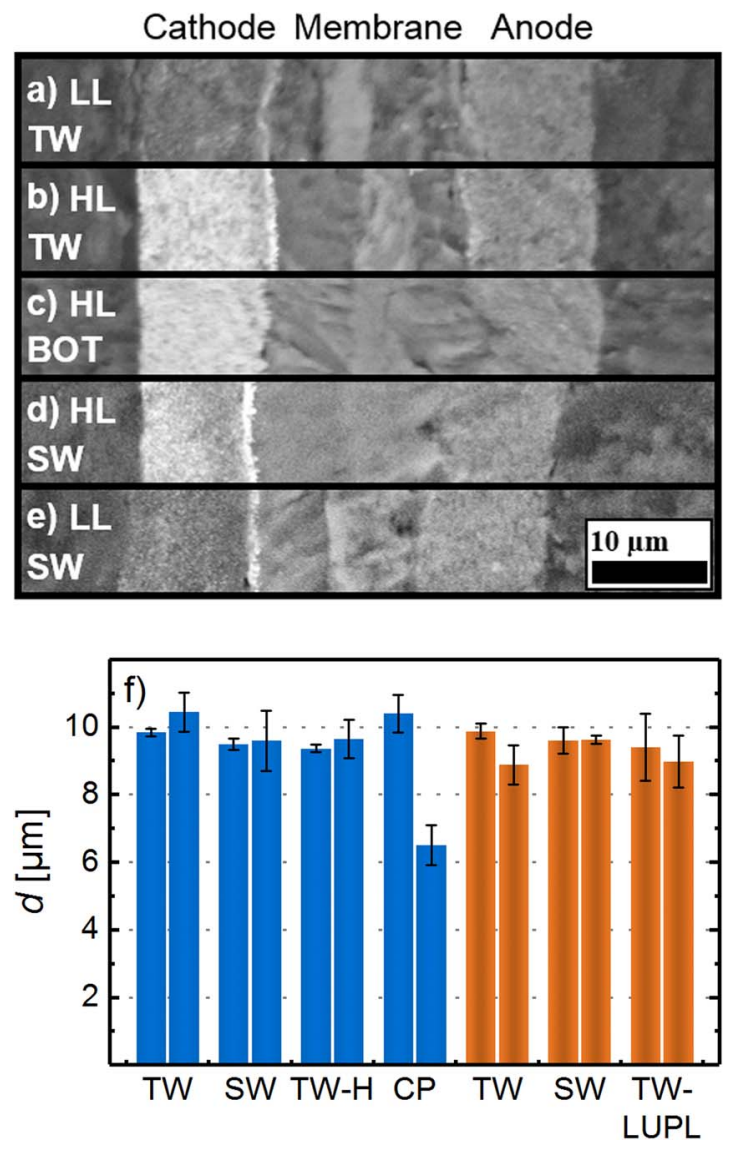

Figure 6. SEM cross-section images of MEAs at BOT and after 30000 potential cycles: low-loaded MEAs $\left(0.1 \mathrm{mg}_{\mathrm{Pt}} / \mathrm{cm}^{2}\right)$ after TW (a) and SW (e) aging between 0.6 and $1.0 \mathrm{~V}_{\mathrm{RHE}}$. High-loaded catalyst layers $\left(0.4 \mathrm{mg}_{\mathrm{Pt}} / \mathrm{cm}^{2}\right)$ of a pristine MEA (c), an MEA after 30000 TW cycles and c) an MEA after SW cycles between 0.6 and $1.0 \mathrm{~V}_{\mathrm{RHE}}$. Images were taken by SEM at a magnification of 2000x in electron back-scattering mode. f) Average cathode thickness of MEAs subjected to different aging protocols both at BOT (left-hand bars in each group) and at EOT (right-hand bars in each group), with high-/ and low-loaded cathodes shown in blue/orange color, respectively. The error bars represent the standard deviation between two independently conducted experiments for each aging protocol; voltage cycling aging protocols are described in Figure 2 and $\mathrm{CP}$ refers to cathodes subjected to an 8 hour potential hold at $1.2 \mathrm{~V}_{\text {cell }}$ (under $\mathrm{N}_{2}$ at $95^{\circ} \mathrm{C}, 100 \% R H$, and $100 \mathrm{kPa}_{\mathrm{abs}}$ ).

cathode electrodes which had been subjected to voltage cycling tests, whose thicknesses was found not to change between EOT and BOT, as is shown in Figure 6f. Quite clearly, carbon support corrosion must be rather minor over 30000 voltage cycles between 0.6 and $1.0 \mathrm{~V}_{\mathrm{RHE}}$ since any significant carbon corrosion is accompanied by cathode thinning (noticeable once ca. 5-7\% carbon are corroded) ${ }^{53}$ However, we cannot fully exclude the possibility that a small extent of carbon corrosion might occur (small enough to not lead to cathode thinning), which then could contribute to the observed ECSA degradation by a particle detachment mechanism. To determine the effect of substantial carbon support corrosion on the ECSA, cathodes were held for 8 hours at $1.2 \mathrm{~V}_{\text {cell }}$ (under $\mathrm{N}_{2}$ at $95^{\circ} \mathrm{C}, 100 \% R H$, and $100 \mathrm{kPa}_{\mathrm{abs}}$ ), which resulted in a decrease of the catalyst layer thickness by $\approx 40 \%$; despite the large extent of carbon corrosion, the ECSA remained at a reasonably large value of $\approx 22 \mathrm{~m}_{\mathrm{Pt}}^{2} / \mathrm{g}$ (blue asterisks in Figure 5).

To obtain further insights into the origin of the faster degradation upon SW aging, seeking to differentiate between ECSA loss caused by the holding time at high potential which might enhance Pt loss into the membrane phase and that originating from the fast Pt oxidation/reduction transient in SW cycling, the potential step in the SW protocol was replaced by a potential sweep with the same scan-rate as in the TW protocol (Figure 2c). This voltage cycling AST is re- ferred to as TW-H. As shown in Figure 5, the decrease of the cathode ECSA over the course of SW (blue long-dashed line, diamonds) and TW-H (blue short-dashed line, triangles) is identical, indicating that the rapid potential transient has no influence on the ECSA degradation and that it is rather the holding time at each potential that is the controlling factor. This can either be explained by the higher oxide coverage of $\mathrm{Pt}$ formed at longer holds at high potential, which Gilbert et al. hypothesized to lead to a larger extent of Pt dissolution during a subsequent step to lower potentials at which the oxide is reduced, leading to faster ECSA losses for SW profiles. ${ }^{51,39}$ An alternative explanation is that the holding time at high potentials allows for a longer time of $\mathrm{Pt}$ dissolution and subsequent diffusion in the ionomer phase towards the cathode/membrane interface, where it can deposit as electrically insulated particles by reduction with cross-over hydrogen. The latter mechanism would explain the apparently higher accumulation of $\mathrm{Pt}$ at the cathode/membrane interface for the $\mathrm{SW}$ compared to the TW modulation suggested qualitatively by the above SEM analysis (compare Figures $6 \mathrm{a} / 6 \mathrm{~b}$ and $6 \mathrm{~d} / 6 \mathrm{e}$ ). Therefore, our experiments suggest that the faster degradation by SW cycling is caused by a more severe Pt dissolution and simultaneously allowing sufficient time for Pt diffusion towards the cathode/membrane interface and its deposition as electrically insulated particles, rather than by carbon support corrosion or the fast voltage transient. It shall be mentioned that the aging per time interval was in fact smaller for TW-H compared to SW, since both methods showed a similar degradation per cycle while one scan in the TW-H procedure required double the time $(32 \mathrm{sec})$ compared to $\mathrm{SW}(16 \mathrm{sec})$. However, the cathode potential remains below $0.9 \mathrm{~V}_{\mathrm{RHE}}$ for a substantial fraction of the time, while we believe that higher potentials are most detrimental for the ECSA.

To probe the degradation at lower potentials, a triangular scan procedure with a lower upper potential limit (TW-LUPL) of $0.85 \mathrm{~V}_{\mathrm{RHE}}$ (orange star symbols and short-dotted lines in Figure 5) was tested. In this case, carbon corrosion most certainly will not play a role, so that aging from $\mathrm{Pt}$ detachment from the carbon support can surely be excluded (the above analysis suggests, carbon corrosion is not a major contributor to ECSA loss even for upper potentials as high as $\left.1.0 \mathrm{~V}_{\mathrm{RHE}}\right)$. In addition, Pt dissolution/redeposition effects should also decrease substantially, since the degree of Pt surface oxidation is limited, leading to less $\mathrm{Pt}$ dissolution, hence to a smaller overall ECSA loss (40\% after 30000 aging cycles) ${ }^{20}$ Since the ECSA loss during TW-LUPL is comparatively low, we conclude that most of the additional time during TW-H compared to SW is non-damaging, e.g. below $0.85 \mathrm{~V}_{\mathrm{RHE}}$. We therefore believe that the lower amount of ECSA loss per time (not per cycle) in the TW-H procedure can be mainly attributed to the additional time at these low, non-damaging potentials. In the light of the rather small ECSA loss when limiting the upper potential to $0.85 \mathrm{~V}_{\mathrm{RHE}}$ (TW-LUPL) compared to the TW aging protocols with an upper potential limit of $1.0 \mathrm{~V}_{\mathrm{RHE}}$ for which ECSA losses of $\approx 90 \%$ over 30000 cycles are observed, avoiding high voltages (e.g., OCV) appears highly advisable to maximize PEMFC durability.

AST induced ORR activity changes.-Assuming simple Tafel kinetics for the ORR according to Equation 1, lowering the cathode $r f$ over the course of ASTs should directly cause an increase of the ORR overpotential according to: 6,54

$$
\eta=T S \cdot\left[\lg \left(\frac{i}{i_{0}} \cdot \frac{1}{r f}\right)\right]
$$

where $\eta$ denotes the ORR overpotential in $\mathrm{mV}$, TS is the Tafel slope in $\mathrm{mV} / \mathrm{dec}, i$ denotes the current density in $\mathrm{A} / \mathrm{cm}^{2}, i_{0}$ is the exchange current density in $\mathrm{A} / \mathrm{cm}_{\mathrm{Pt}}^{2}$, and $r f$ denotes the roughness factor in $\mathrm{cm}_{\mathrm{Pt}}^{2} / \mathrm{cm}^{2}$

In Figure $7 \mathrm{a}$, differential flow $\mathrm{H}_{2} / \mathrm{O}_{2}$ polarization curves at $80^{\circ} \mathrm{C}$ and $100 \% R H$ are shown for all AST protocols at BOT and after 30000 aging cycles. First of all, a voltage offset is observed in the initial polarization curves of low-loaded (solid orange lines) compared to high-loaded (solid blue lines) cathodes at BOT. Based on simple Tafel 


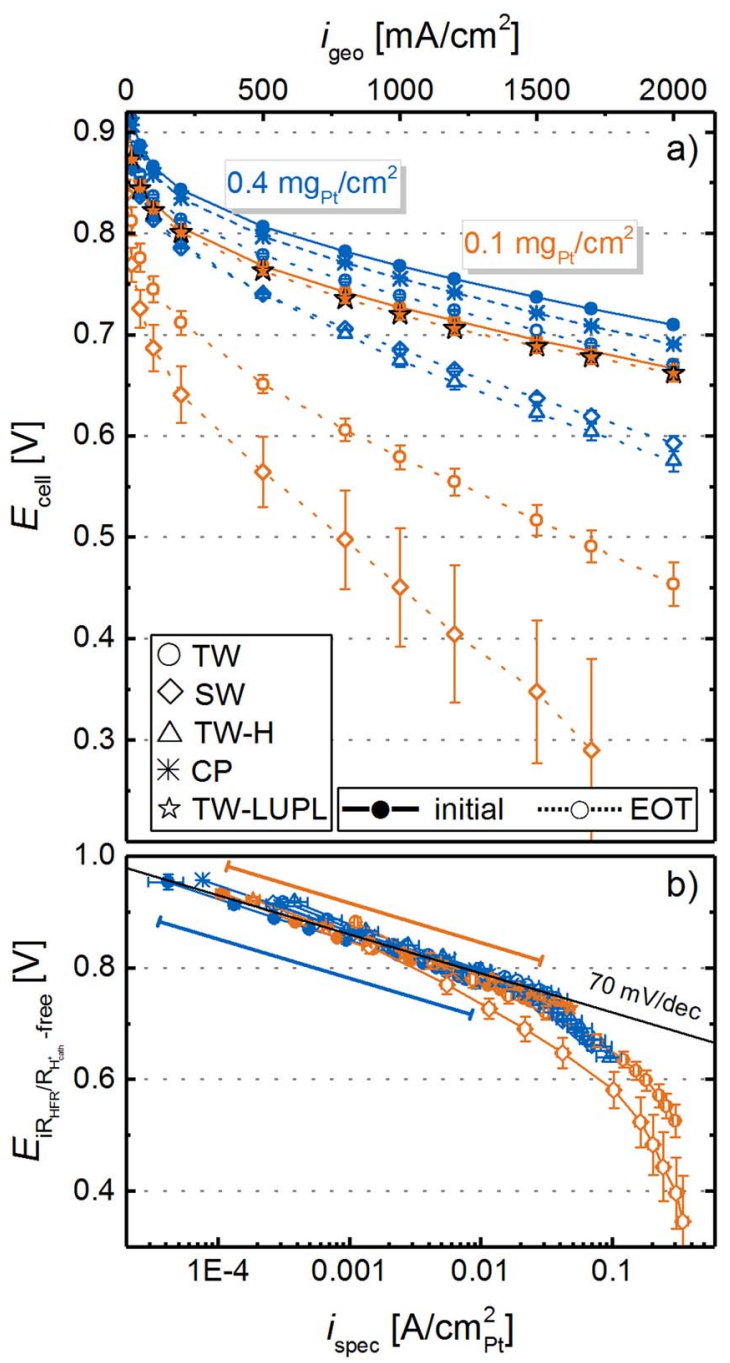

Figure 7. Differential flow $\mathrm{H}_{2} / \mathrm{O}_{2} \quad(2000 / 5000$ nccm $)$ performance for MEAs with $0.4 \mathrm{mg}_{\mathrm{Pt}} / \mathrm{cm}^{2}$ (blue lines/symbols) and $0.1 \mathrm{mg} \mathrm{gt}_{\mathrm{Pt}} / \mathrm{cm}^{2}$ (orange lines/symbols) cathodes at BOT (solid lines and filled symbols) and at EOT, i.e., after 30000 voltage cycles or an 8 hour hold at $1.2 \mathrm{~V}_{\text {cell }}$ (dotted lines or hollow symbols). a) Measured cell voltage curves at a pressure of $170 \mathrm{kPa}_{\mathrm{abs}}$, a temperature of $80^{\circ} \mathrm{C}$, and an $R H$ of $100 \%$. b) Tafel plot representation normalized to the ECSA, corrected by the HFR, the effective proton conduction resistance, as well as by the $\mathrm{H}_{2}$ crossover and electrical short current. BOT polarization curves of all tested MEAs were averaged and error bars represent the standard deviation of all tested MEAs. Error bars for EOT curves represent the mean absolute deviation between two measurements. The two slanted lines in b) indicate the specific current density region for high-loaded (blue) and low-loaded (orange) MEAs at BOT.

kinetics (Equation 1) and an ORR Tafel slope of $70 \mathrm{mV} / \mathrm{dec}$, four times lower Pt cathode loadings should result in an approximately four times lower roughness factor (as the catalyst ECSA is very similar) and thus to an additional overpotential of $\approx 42 \mathrm{mV}$ at the same current density, which is in excellent agreement with the observed offset between highand low-loaded MEAs (e.g., $737 \pm 3 \mathrm{mV}$ vs $695 \pm 8 \mathrm{mV}$ at $1.5 \mathrm{~A} / \mathrm{cm}^{2}$ $(42 \pm 11 \mathrm{mV})$ for high- and low-loaded electrodes, respectively).

Over the course of 30000 voltage cycles (三 EOT condition), the polarization curves of all tested MEAs degrade significantly, with a more severe performance decay for low-loaded MEAs (e.g., $214 \mathrm{mV}$ loss at $2 \mathrm{~A} / \mathrm{cm}^{2}$ for the TW protocol) compared to high-loaded MEAs ( $39 \mathrm{mV}$ loss at $2 \mathrm{~A} / \mathrm{cm}^{2}$ ). When comparing polarization curves from different aging protocols, the previously identified higher ECSA loss for SW compared to TW cycling correlates well with the observed performance difference in the $\mathrm{O}_{2}$ polarization curve at EOT for both loadings. Furthermore, a similar performance decay is observed for the TW-H and SW protocol, e.g., a voltage of $593 \pm 8 \mathrm{mV}$ for $\mathrm{SW}$ and $575 \pm 1 \mathrm{mV}$ for TW-H at $2 \mathrm{~A} / \mathrm{cm}^{2}$ and EOT, which is in accordance with the comparable loss of ECSA. In contrast to the other AST protocols, EOT polarization curves for the TW-LUPL protocol do not show any degradation compared to BOT, reflecting the comparably low degradation of the ECSA.

To determine the specific ORR activity for each MEA, the polarization curves were corrected by the $H F R\left(R_{H F R}\right)$, the $\mathrm{H}_{2}$ crossover current $\left(\mathrm{i}_{\mathrm{H}_{2} \text {-cross }}\right.$, on the order of $\left.\approx 4 \mathrm{~mA} / \mathrm{cm}^{2}\right)$, the shorting current $\left(i_{\text {short }}\right)$, the effective proton conduction resistance in the cathode catalyst layer $\left(R_{\mathrm{H}^{+}}^{\text {cath,eff }}\right)$, and were normalized to the Pt surface area (Figure $7 \mathrm{~b}$ ). As expected for $\mathrm{H}_{2} / \mathrm{O}_{2}$ polarization curves dominated by kinetic overpotentials, all data points fall on a straight line, with a BOT Tafel slope of $70 \pm 3 \mathrm{mV} / \mathrm{dec}$ for high-loaded and $73 \pm 3 \mathrm{mV} / \mathrm{dec}$ for the lowloaded MEAs. After 30000 voltage cycles, the apparent Tafel slope of high-loaded MEAs, determined in the low current density region (50-500 mA/ $\mathrm{cm}^{2}$ ), increases to $79 \pm 1 \mathrm{mV} / \mathrm{dec}$ for TW aged MEAs and more significantly $(\approx 90 \mathrm{mV} / \mathrm{dec})$ for the $\mathrm{SW}$ and $\mathrm{TW}-\mathrm{H}$ aging protocols. Tafel slopes of around $120-160 \mathrm{mV} / \mathrm{dec}$ were observed for low-loaded MEAs subjected to $30000 \mathrm{TW}$ and SW cycle protocols, while the Tafel slope remained unchanged over the course of the TWLUPL voltage cycling AST. An increasing Tafel slope upon aging was also observed by other researchers, ${ }^{21}$ and is attributed to additional, non-kinetic overpotentials, such as $\mathrm{O}_{2}$ mass transport or proton transport losses which apparently increase with extended voltage cycling. Since the electrode thickness remained unchanged (Figure 6f), even for the most damaging aging protocols (SW and TW-H), a hindrance of the gas phase mass transport caused by a deterioration of the overall catalyst layer structure can be excluded. Although, slight corrosion of the catalyst support and a concomitant slight decrease of the available pore volume cannot be fully excluded, cathode thinning was clearly not observed by SEM in any of our experiments. Additionally, changes of the Tafel slope due to loss or restructuration of the ionomer can be excluded as the proton transport resistance did not change significantly upon voltage cycling (not shown) and major chemical degradation of the ionomer can be excluded due to the absence of oxygen in the largest fraction of the experimental time. ${ }^{56}$

We would like to emphasize that these measurements were performed with pure $\mathrm{O}_{2}$, where gas phase $\mathrm{O}_{2}$ transport resistances can be excluded as possible cause for the increasing apparent Tafel slopes. It is also worth noting that these severe and unassigned mass transport overpotentials occur at similar values of the $\mathrm{Pt}$ specific current density (near $\approx 0.05 \mathrm{~A} / \mathrm{cm}_{\mathrm{Pt}}^{2}$ ) in all $\mathrm{H}_{2} / \mathrm{O}_{2}$ polarization curves. At high $\mathrm{Pt}$ specific current densities, caused by ultra-low $r f$ values, additional voltage losses have also been observed by other researchers. ${ }^{9,10,55}$ Since this overpotential occurs at high geometric current densities and low cathode $r f$ values, i.e., at high local oxygen flux to the $\mathrm{Pt}$ surface, we hypothesize that it is related to oxygen transport limitations at the catalyst/ionomer interface. Suggestions for the observed voltage losses at high Pt-specific currents by other research groups include a limited dissolution of oxygen into the ionomer phase, ${ }^{57}$ an intrinsically high transport resistance of the thin ionomer phase, ${ }^{58}$ a limited effective ionomer surface, ${ }^{10,37}$ or a decrease of the ORR kinetics at low potential. ${ }^{59}$ Although we cannot exclude any one of these effects, a Pt/ionomer specific resistance appears most reasonable to explain the observed voltage losses at high Pt-specific currents, as the voltage profile shows a shape resembling a mass transport limitation, rather than a kinetic phenomenon.

A linear regression of the measured data in the current density range from 50 to $500 \mathrm{~mA} / \mathrm{cm}^{2}$ and extrapolation to $0.9 \mathrm{~V}_{\mathrm{RHE}}$ yields the kinetic ORR activity at $0.9 \mathrm{~V}_{\mathrm{RHE}}$ (at $120 \mathrm{kPa}_{\mathrm{abs}} \mathrm{O}_{2}$ partial pressure), commonly used to compare the catalytic activity of platinum. It can either be normalized to the measured ECSA to yield the specific current density for the ORR at $0.9 \mathrm{~V}_{\mathrm{RHE}}\left(\mathrm{i}_{0.9 \mathrm{~V}}^{\mathrm{spec}}\right.$, Figure $\left.8 \mathrm{~b}\right)$ or to the mass of $\mathrm{Pt}$ in the cathode catalyst layer to yield the mass activity for the ORR at $0.9 \mathrm{~V}_{\mathrm{RHE}}\left(\mathrm{i}_{0.9 \mathrm{~V}}\right.$, Figure $\left.8 \mathrm{a}\right)$ to enable comparability between all experiments. In general, the here determined ORR 


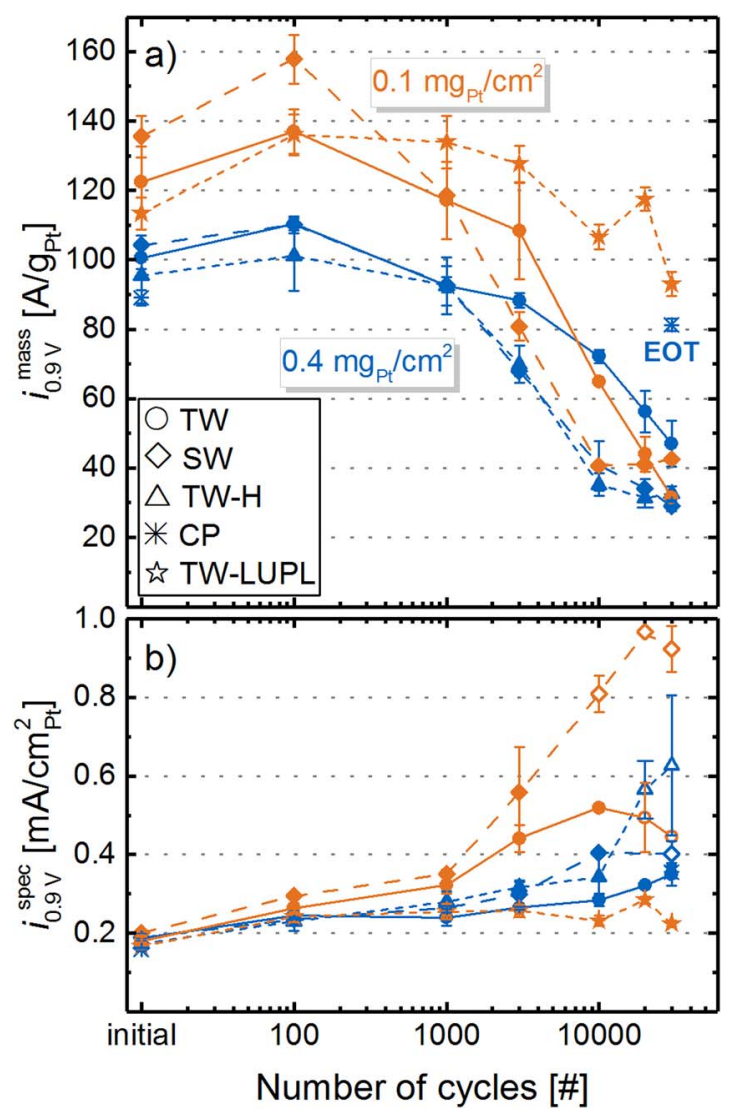

Figure 8. a) ORR mass activity at $0.9 \mathrm{~V}\left(i_{0.9 \mathrm{~V}}^{\text {mass }}\right)$ and b) ORR specific activity at $0.9 \mathrm{~V}\left(i_{0.9 \mathrm{~V}}^{\text {spec }}\right)$ extracted from Figure 7 for MEAs with $0.4 \mathrm{mg}_{\mathrm{Pt}} / \mathrm{cm}^{2}$ (blue lines/symbols) and $0.1 \mathrm{mg}_{\mathrm{Pt}} / \mathrm{cm}^{2}$ (orange lines/symbols) cathodes over the course of various ASTs. The exchange current density at $0.9 \mathrm{~V}$ was obtained by a linear regression of fully corrected polarization curves in $\mathrm{O}_{2}$ between 50 and $500 \mathrm{~mA} / \mathrm{cm}^{2}$.

mass activities at BOT $\left(\approx 110-140 \mathrm{~A} / \mathrm{g}_{\mathrm{Pt}}\right.$ for the $20 \%_{\mathrm{wt}} \mathrm{Pt} / \mathrm{V}$ catalyst and $\approx 85-105 \mathrm{~A} / \mathrm{g}_{\mathrm{Pt}}$ for the $50 \%_{\mathrm{wt}} \mathrm{Pt} / \mathrm{V}$ catalyst) compare well with those reported by other researchers for Pt supported on Vulcan type carbon. ${ }^{7,60,61}$ In accordance with the severe ECSA loss in most of the here examined aging protocols, the overall surface available for the ORR decreases significantly from BOT to EOT (low-loaded TW, SW and TW-H: $\approx 90 \%$ ECSA loss), there is also a significant loss of $\mathrm{i}_{0.9}^{\text {mass }}$ over the course of aging for all loadings and aging procedures (see Figure 8a). Comparing TW (solid lines, circles) and SW (long-dashed lines, diamonds), the decrease of $\mathrm{i}_{0.9 \mathrm{~V}}^{\text {mass }}$ as a function of cycle number is more pronounced for SW profiles, which is directly correlated to the stronger ECSA loss (see Figure 5). To clarify, the accelerated decrease of $\mathrm{i}_{0.9 \mathrm{~V}}^{\text {mass }}$ by $\mathrm{SW}$ compared to TW modulations most likely represents a true change in the ORR kinetics, as interference from $\mathrm{O}_{2}$ mass transport resistances in pure $\mathrm{O}_{2}$ in the low current density region (data evaluation was restricted to a maximum current density of $500 \mathrm{~mA} / \mathrm{cm}^{2}$ ) should be negligible. This assumption is reasonably justified since only a slight increase in the apparent Tafel slope was observed upon aging (e.g., $70 \pm 3 \mathrm{mV} / \mathrm{dec}$ at BOT increases to $86 \pm$ $2 \mathrm{mV} / \mathrm{dec}$ at EOT for high-loaded SW cycled cathodes) and since we eliminated regions at high specific current density (where local transport resistances could be important) from the analysis. As expected from our preceding analysis of the ECSA development (see Figure 5), the mass activity of electrodes aged by TW-H cycles is essentially identical to those aged by SW cycles (compare blue triangle and diamond symbols in Figure 8a), underlining our previous hypothesis that the potential hold phase is the dominating factor for MEA degradation during square wave aging. Finally, the ORR mass activity loss over the TW-LUPL procedure (orange stars) is significantly lower compared to the other protocols, which again is in accordance with the lower ECSA loss.

It is interesting to note that in contrast to the overall trend of decreasing ORR mass activity, $i_{0.9 \mathrm{~V}}^{\text {mass }}$ reaches a maximum after 100 cycles, particularly noticeable for low-loaded MEAs. This could be ascribed to an activation of the catalyst particles due to cleaning of the Pt surface, which might overcompensate the ECSA loss of $\approx 20 \%$ in the initial 100 cycles. If true, this would mean that the initial activation procedure (see experimental section) was not sufficient to fully activate the cathode catalyst layer. Alternatively, there is the possibility that the measurement sequence (described in Figure 1) might influence the observed small variation of the measured ORR activity. While the $\mathrm{O}_{2}$ polarization curves at BOT as well as at 10000, and at 30000 cycles were recorded after polarization curves in $10 \% \mathrm{O}_{2}$ and in air (each approximately $3.5 \mathrm{~h}$ ), all other $\mathrm{O}_{2}$ polarization curves were recorded directly after a recovery step. Thus, it is possible that after these two polarization curves without an intermediate recovery step, a certain extent of reversible degradation (i.e., Pt poisoning) might have occurred, ${ }^{62}$ resulting in a lower ORR mass activity. Evidence for this behavior can be seen for the low-loaded MEAs tested with the TW-LUPL procedure (orange stars in Figure 8a), where ORR mass activities were always higher when measured directly after a recovery step (i.e., at 100, 1000, 3000 and 20000 cycles), while reproducibly lower values were obtained in the absence of a directly preceding recovery step (at BOT as well as at 10000 and 30000 cycles). Since the overall degradation rate induced by the TW-LUPL procedure is rather small ( $\approx 40 \%$ loss in ECSA and $i_{0.9 \mathrm{~V}}$ afs after 30000 cycles), this presumably testing procedure related inaccuracy of $\approx 10 \%$ in the quantification of $i_{0.9 \mathrm{~V}}^{\text {mass }}$ might have become apparent. Nevertheless, this minor uncertainty in ORR mass activity values is of no consequence to the conclusions drawn from these data

Further insights into the aging process can be obtained by examining the specific ORR activity at $0.9 \mathrm{~V}_{\mathrm{RHE}}, i_{0.9 \mathrm{~V}}^{\text {spec }}$, as shown in Figure 8 b. It is well-known that small Pt nanoparticles have a lower specific ORR activity due to their relatively larger amount of edge and corner sites compared to larger nanoparticles. ${ }^{63}$ Amongst others, Mayrhofer et al. found an increase of the specific activity of Pt particles by a factor $\approx 2$ when going from $1 \mathrm{~nm}$ sized particles to $5 \mathrm{~nm} .{ }^{64} \mathrm{In}$ our case, the determined specific ORR activities of low-loaded (182 \pm $\left.18 \mu \mathrm{A} / \mathrm{cm}_{\mathrm{Pt}}^{2}\right)$ and high-loaded MEAs $\left(177 \pm 16 \mu \mathrm{Acm}_{\mathrm{Pt}}^{2}\right)$ at BOT are essentially identical, consistent with the very similar average particle size of the two catalysts $(2.8 \pm 0.8 \mathrm{~nm}$ for $20 \% \mathrm{wt}$ Pt/C and $3.2 \pm$ $1.0 \mathrm{~nm}$ for $\left.50 \%_{\mathrm{wt}} \mathrm{Pt} / \mathrm{C}\right)$. In the course of aging, the specific activity increases for all tested MEAs due to the constantly growing fraction of larger particles. The highest observed ORR activity $\left(\approx 1 \mathrm{~mA} / \mathrm{cm}_{\mathrm{Pt}}^{2}\right)$ was found for low-loaded catalyst layers with the most significant ECSA loss (Figure 5) due to the harsh SW aging protocol. However, it shall be noted that the determination of the catalyst activity is slightly impaired by an increased Tafel slope for MEAs with a very small $r f$ value, hence the calculation of $i_{09 \mathrm{~V}}^{\text {spec }}$ becomes increasingly erroneous for strongly aged catalyst layers due to difficulties in determining kinetic parameters accurately.

AST induced $\mathrm{H}_{2}$ /air and $\mathrm{H}_{2} / 10 \% \mathrm{O}_{2}$ performance losses.-To obtain further information about mass transport related overpotentials induced by the different aging protocols, polarization curves in air and $10 \% \mathrm{O}_{2}$ (to simulate conditions at the cathode outlet of a PEMFC stack operated at an air stoichiometry of $\approx 1.75$ ) were measured at several aging stages (Figure 9). The solid lines are the average BOT performance of MEAs with $0.4 \mathrm{mg}_{\mathrm{Pt}} / \mathrm{cm}^{2}$ (blue) and $0.1 \mathrm{mg}_{\mathrm{Pt}} / \mathrm{cm}^{2}$ (orange) cathode loadings at the here investigated operating conditions of $170 \mathrm{kPa}_{\mathrm{abs}}, 80^{\circ} \mathrm{C}$, and $100 \% \mathrm{RH}$ (error bars represent the standard deviation across all measured MEAs, indicating the excellent reproducibility of the performance at BOT). Similarly to polarization curves in $\mathrm{O}_{2}$ (Figure 7a), a clear offset between high-loaded and lowloaded cathodes, resulting from a different cathode $r f$, is observed for BOT polarization curves in air (e.g., $689 \pm 3 \mathrm{mV}$ vs $634 \pm 10 \mathrm{mV}$ at $1.5 \mathrm{~A} / \mathrm{cm}^{2}$ for high- and low-loaded electrodes, respectively) and $10 \%$ $\mathrm{O}_{2}$ (e.g., $620 \pm 10 \mathrm{mV}$ vs $496 \pm 9 \mathrm{mV}$ at $1.5 \mathrm{~A} / \mathrm{cm}^{2}$ for high- and 


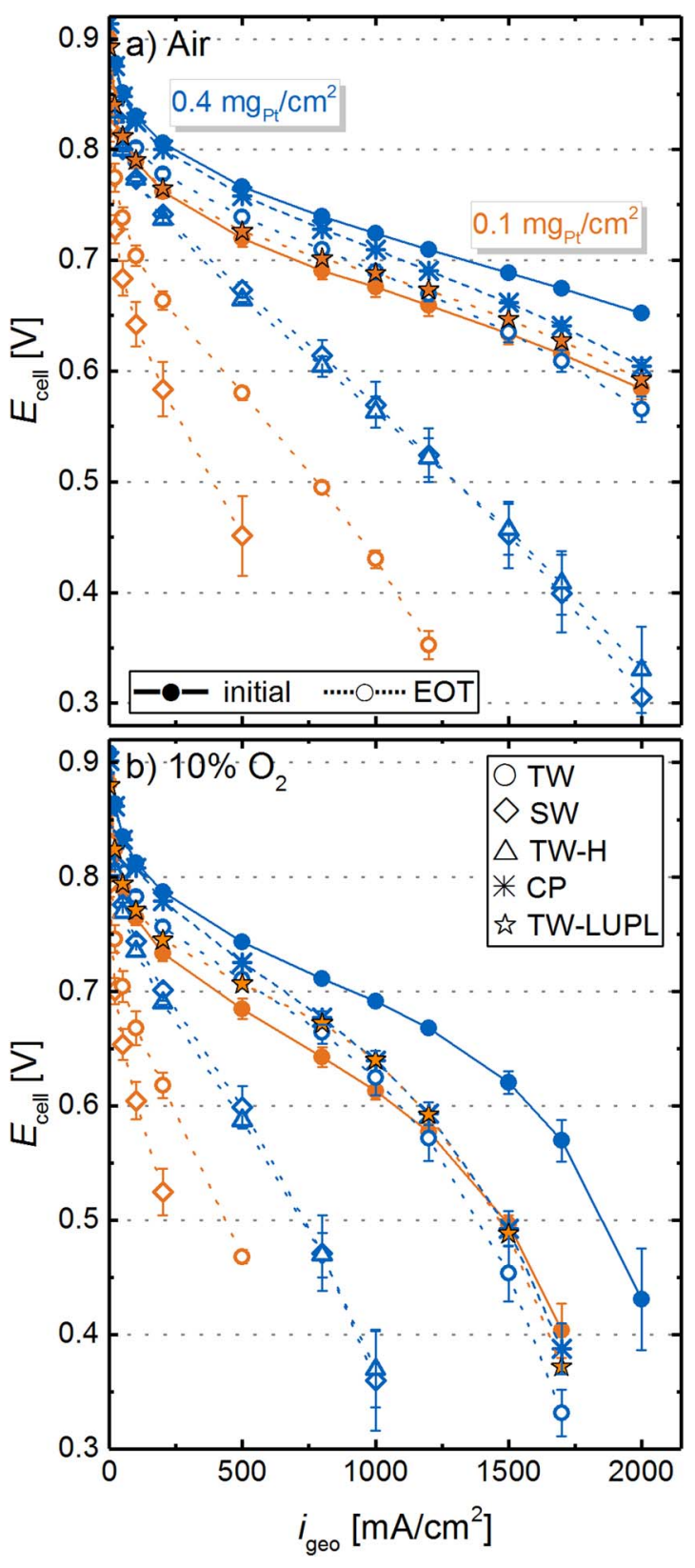

Figure 9. Differential flow a) $\mathrm{H}_{2} /$ air and b) $\mathrm{H}_{2} / 10 \% \mathrm{O}_{2}$ (2000/5000 nccm) performance $\left(170 \mathrm{kPa}_{\mathrm{abs}}, 80^{\circ} \mathrm{C}\right.$, and $\left.100 \% \mathrm{RH}\right)$ for MEAs with $0.4 \mathrm{mg} \mathrm{gt}_{\mathrm{P}} / \mathrm{cm}^{2}$ (blue lines/symbols) and $0.1 \mathrm{mg}_{\mathrm{Pt}} / \mathrm{cm}^{2}$ (orange lines/symbols) cathodes at BOT (solid lines and filled symbols) and at EOT, i.e., after 30000 voltage cycles or an 8 hour hold at $1.2 \mathrm{~V}_{\text {cell }}$ (dotted lines or hollow symbols). BOT polarization curves of all tested MEAs were averaged and error bars represent the standard deviation of all measurement points. At EOT, error bars represent the mean absolute deviation of two measurements.

low-loaded electrodes, respectively). In contrast to pure $\mathrm{O}_{2}$, where the offset perfectly matched the increase of $\eta_{\mathrm{ORR}}$ predicted by Equation 1, the voltage loss for low-loaded MEAs in air (e.g., $55 \pm 13 \mathrm{mV}$ at $1.5 \mathrm{~A} / \mathrm{cm}^{2}$ ) and $10 \% \mathrm{O}_{2}$ (e.g., $124 \pm 19 \mathrm{mV}$ at $1.5 \mathrm{~A} / \mathrm{cm}^{2}$ ) was much higher than the kinetically expected penalty. The additional voltage loss for low-loaded cathodes in air, being even more pronounced in $10 \% \mathrm{O}_{2}$, is an initial hint on a mass transport overpotential related to the $r f$ value of the cathode. Several other researchers reported the occurrence of such a $\mathrm{Pt}$ surface area specific $\mathrm{O}_{2}$ mass transport resistance (termed $R_{\mathrm{O}_{2}}^{\mathrm{Pt}}$ in this manuscript) for pristine cathodes with different loadings and showed its substantial increase with decreasing cathode $r f$ values by limiting current measurements. ${ }^{8-10,41}$
High-loaded MEAs aged by the SW and TW-H protocol (open blue diamonds and triangles in Figure 9) show a similar performance at EOT, which was significantly lower compared to MEAs aged by the TW protocol (open blue circles). This is in accordance with the above discussed $\mathrm{O}_{2}$ polarization curves (Figure 7a) and ECSA losses (Figure 5a). Even though the overall performance losses are rather dramatic for the low-loaded MEAs, they also show the same increased aging when subjected to SW rather than TW voltage cycling (open orange diamonds and circles). However, as one might have hoped based on the ECSA (Figure 5) and ORR mass activity (Figure 8a) data, even with low-loaded cathodes no voltage cycling induced performance losses occur over 30000 cycles when using the TW-LUPL protocol with a lowered upper voltage limit of $0.85 \mathrm{~V}_{\mathrm{RHE}}$, neither in $\mathrm{H}_{2}$ /air nor in $\mathrm{H}_{2} / 10 \% \mathrm{O}_{2}$ (orange stars in Figure 9).

An interesting insight into the $r f$ dependent $R_{\mathrm{O}_{2}}^{\mathrm{Pt}}$ induced losses can be gained by comparing the $\mathrm{H}_{2}$ /air EOT performance of the high-loaded cathode subjected to TW cycling (open blue circles) and the low-loaded cathode subjected to TW-LUPL cycling (orange stars). At EOT, the high-loaded cathode has a slightly higher roughness factor $\left(56 \pm 12 \mathrm{~cm}_{\mathrm{Pt}}^{2} / \mathrm{cm}^{2}\right)$ compared to the low-loaded cathode $\left(42 \pm 2 \mathrm{~cm}_{\mathrm{Pt}}^{2} / \mathrm{cm}^{2}\right)$, so that one would expect a similar or an even lower $R_{\mathrm{O}_{2}}^{\mathrm{Pt}}$ value for the former. At the same time, the specific ORR activity at $0.9 \mathrm{~V}_{\mathrm{RHE}}$ for the high-loaded cathode $(350 \pm 29$ $\mu \mathrm{A} / \mathrm{cm}_{\mathrm{Pt}}^{2}$ ) is substantially larger than that for the low-loaded cathode $\left(224 \pm 7 \mu \mathrm{A} / \mathrm{cm}_{\mathrm{Pt}}^{2}\right)$. Since the product of $\left(i_{0.9 \mathrm{~V}}^{\mathrm{spec}} \cdot r f\right)$, equating to 19.6 $\mathrm{mA} / \mathrm{cm}_{\mathrm{Pt}}^{2}$ for the high-loaded and $9.2 \mathrm{~mA} / \mathrm{cm}_{\mathrm{Pt}}^{2}$ for the low-loaded cathode, is proportional to $\left(i_{0} \cdot r f\right)$ under the same operating conditions, the $\eta_{\text {ORR }}$ difference predicted by Equation 1 is $\approx 23 \mathrm{mV}$, suggesting that the kinetically predicted EOT performance of the high-loaded cathode subjected to TW cycles should be $\approx 23 \mathrm{mV}$ higher than that of the low-loaded cathode subjected to TW-LUPL cycles. This is consistent with the higher $\mathrm{H}_{2} / \mathrm{O}_{2}$ performance of the former (see Figure 7a) and also its superior low current density performance in $\mathrm{H}_{2}$ /air or $\mathrm{H}_{2} / 10 \% \mathrm{O}_{2}$ (see Figure 9). However, despite its higher EOT roughness factor, the TW-aged high-loaded cathode exhibits a larger (unassigned) mass transport loss, evident by its lower $\mathrm{H}_{2} /$ air or $\mathrm{H}_{2} / 10 \% \mathrm{O}_{2}$ performance at current densities above $\approx 1 \mathrm{~A} / \mathrm{cm}^{2}$ (see Figure 9). Since no significant differences in the effective proton conduction resistance (measured by EIS) were observed between these two electrodes, an apparently larger oxygen transport resistance, which is not simply related to the cathode $r f$ value and produced by voltage cycling, must exist. Its origin is unclear at the moment, but it may be related to the morphological changes and redistribution of $\mathrm{Pt}$ within the cathode electrode caused by voltage cycling.

$\mathrm{O}_{2}$ transport resistance evaluation.-In order to disentangle mass transport resistances originating from gas transport in the flow fields and the GDL from those in the catalyst layer, and to identify resistances dependent on the cathode $r f$ value, limiting current measurements were executed according to the method developed by Baker et al. ${ }^{36}$ In this approach, the concentration of $\mathrm{O}_{2}$ (dry gas fraction in $\mathrm{N}_{2}$ ) in the feed gas is varied from $4 \%$ to $24 \%$, while a low potential between 0.05 and $0.30 \mathrm{~V}$ is applied to obtain the limiting current, where the $\mathrm{O}_{2}$ concentration at the $\mathrm{Pt}$ surface decreases to zero and the current-voltage profiles at different $\mathrm{O}_{2}$ concentrations resemble a vertical line (see Figure 10a). For each concentration, the $\mathrm{O}_{2}$ mass transport resistance is calculated and plotted versus the respective limiting current density, as illustrated in Figure 10b for the low-loaded cathode MEAs at BOT and after 30000 SW cycles (for details on the analysis see Simon et al.). ${ }^{32}$

For all cathodes at BOT, the total oxygen mass transport resistance, $R_{\mathrm{O}_{2}}^{\text {total }}$, is essentially independent of the limiting current density at all pressures (see triangles in Figure 10b and its inset), as is expected under these conditions for the Freudenberg GDL. ${ }^{65}$ Furthermore, the determination of the limiting current density at various pressures enables the separation of $R_{\mathrm{O}_{2}}^{\text {total }}$ into a pressure dependent $\left(R_{\mathrm{O}_{2}}^{\mathrm{PD}}\right)$ and a pressure independent $\left(R_{\mathrm{O}_{2}}^{\mathrm{PI}}\right)$ oxygen mass transport resistance via a linear regression of $R_{\mathrm{O}_{2}}^{\text {total }}$ versus the absolute pressure (Figure 10c). 

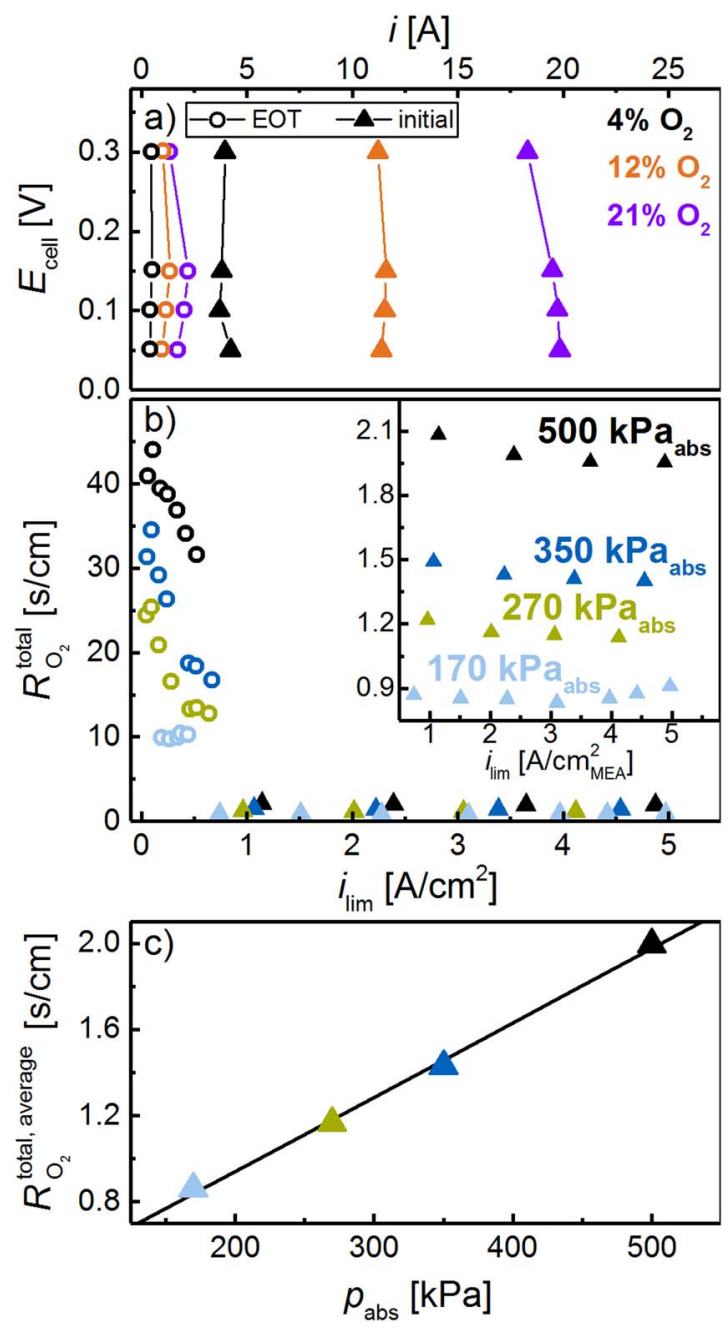

Figure 10. a) Limiting current measurement in the potential range between 0.30 and $0.05 \mathrm{~V}$ at $\mathrm{O}_{2}$ concentrations of $4 \%, 12 \%$, and $21 \%$, comparing a $0.1 \mathrm{mg}_{\mathrm{P}} / \mathrm{cm}^{2}$ cathode at BOT (triangles) and after $30000 \mathrm{SW}$ cycles (circles). Measurements were performed at $80^{\circ} \mathrm{C}, 100 \% \mathrm{RH}$, and $170 \mathrm{kPa}_{\mathrm{abs}}$ (using $2000 \mathrm{nccm} \mathrm{H}_{2}$ and $5000 \mathrm{nccm} \mathrm{O}_{2}$ in $\mathrm{N}_{2}$ ). b) Total $\mathrm{O}_{2}$ mass transport resistance vs limiting current density at $170,270,350$ and $500 \mathrm{kPa}_{\mathrm{abs}}\left(\mathrm{O}_{2}\right.$ concentration between $4 \%$ and $24 \%$ ); the inset is a zoom into the low $R_{\mathrm{O}_{2}}^{\text {total }}$ region at high limiting current densities. c) $R_{\mathrm{O}_{2}}^{\text {total }}$ of the BOT cathode averaged over all $\mathrm{O}_{2}$ concentrations at the respective pressure; the shown linear regression line is used to deconvolute $R_{\mathrm{O}_{2}}^{\text {total }}$ into $R_{\mathrm{O}_{2}}^{\mathrm{PD}}$ and $R_{\mathrm{O}_{2}}^{\mathrm{PI}}$.

Nevertheless, a severe decrease of the limiting current is observed for low-loaded cathodes after extended TW or SW cycling, exemplarily shown in Figure 10a for the SW protocol (BOT $\equiv$ triangles; EOT $\equiv$ circles). At EOT, the limiting current density (circles in Figure 10a) is significantly lower, and the resulting $R_{\mathrm{O}_{2}}^{\text {total }}$ values are more than an order of magnitude larger than at BOT and change severely with limiting current density, especially at higher pressures (circles in Figure 10b). We attribute this unsteady transport resistance at higher pressures to a local catalyst layer/GDL flooding (at an inlet $R H$ of $100 \%$ ) due to the low limiting current, at which no significant through-plane temperature gradient between MEA and flow field can be established, thereby hampering product water removal through the gas phase. This hypothesis is underpinned by the fact that the transport resistance is strongly decreasing with increasing current density, i.e., at a higher temperature gradient. The effect of flooding is even more pronounced at higher applied pressures, analogous to what is generally observed. ${ }^{66}$ As the evaluation of $R_{\mathrm{O}_{2}}^{\text {total }}$ at higher pressure is not reliable in cases like the one shown in Figure 10b (circles), a deconvolution of $R_{\mathrm{O}_{2}}^{\text {total }}$

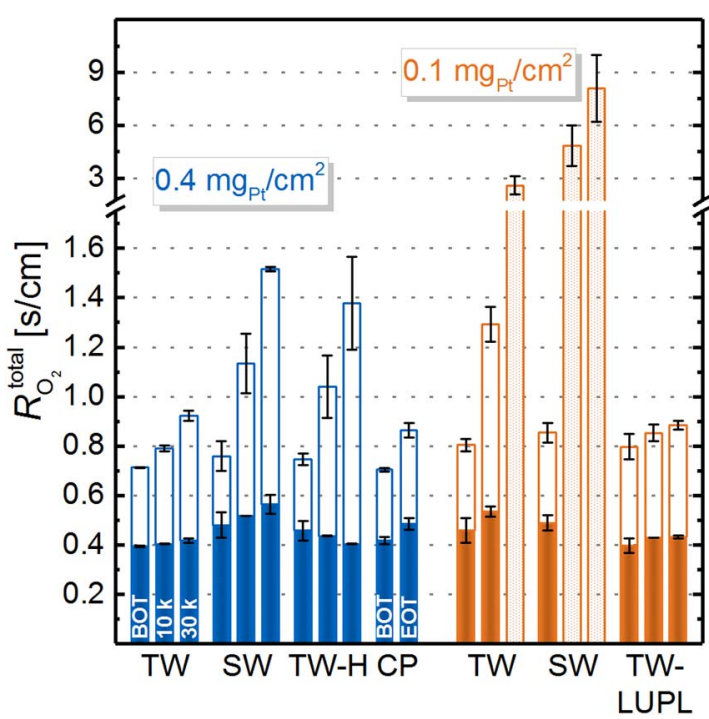

Figure 11. Total oxygen mass transport resistance $\left(R_{\mathrm{O}_{2}}^{\text {total }}\right)$ determined at $80^{\circ} \mathrm{C}, 100 \% \mathrm{RH}$, and $170 \mathrm{kPa}_{\text {abs }}$ (differential flow of hydrogen and $4 \%$ $21 \% \mathrm{O}_{2}$ (balance $\mathrm{N}_{2}$ ) for high-loaded (blue) and low-loaded (orange) cathodes tested by different ASTs (for each, left bars are at BOT, middle bars at 10000 cycles, and right bars 30000 cycles). $R_{\mathrm{O}_{2}}^{\text {total }}$ was also separated into pressure dependent $\left(R_{\mathrm{O}_{2}}^{\mathrm{PD}}\right.$, solid bar) and pressure independent $\left(R_{\mathrm{O}_{2}}^{\mathrm{PI}}\right.$, open bar $)$ oxygen mass transport resistance contributions. For certain experiments, the deconvolution of $R_{\mathrm{O}_{2}}^{\text {total }}$ was not reliable, thus only the total transport resistance at $170 \mathrm{kPa}_{\mathrm{abs}}$ is plotted as a dotted bar. Error bars correspond to the mean absolute deviation of two repeat experiments with different MEAs.

into $R_{\mathrm{O}_{2}}^{\mathrm{PD}}$ and $R_{\mathrm{O}_{2}}^{\mathrm{PI}}$ is not trustworthy, hence only the total transport resistance at $170 \mathrm{kPa}_{\mathrm{abs}}$ is considered in these instances. The origin of this effect is yet unclear, but as will be shown in the following, it is not related to carbon support corrosion.

The total oxygen mass transport resistance at different stages of the aging protocol is shown for high-loaded (blue) and low-loaded (orange) cathodes in Figure 11, separated into pressure dependent, $R_{\mathrm{O}_{2}}^{\mathrm{PD}}$ (solid bars), and pressure independent, $R_{\mathrm{O}_{2}}^{\mathrm{PI}}$ (hollow bars) contributions, according to the above described analysis. All high-loaded (average of $0.73 \pm 0.09 \mathrm{~s} / \mathrm{cm}$ ), as well as all low-loaded cathodes (average of $0.82 \pm 0.10 \mathrm{~s} / \mathrm{cm}$ ) show a similar $R_{\mathrm{O}_{2}}^{\text {total }}$ at BOT, demonstrating a reproducible MEA fabrication. In general, low-loaded cathodes show a slightly higher transport resistance than high-loaded electrodes at BOT, as already indicated by the observed voltage losses in $\mathrm{H}_{2}$ /air (Figure $9 \mathrm{a}$ ) and $\mathrm{H}_{2} / 10 \% \mathrm{O}_{2}$ polarization curves (Figure $9 \mathrm{~b}$ ). The pressure dependent transport resistance associated with the GDL is, as expected, essentially identical for high- $\left(R_{\mathrm{O}_{2}}^{\mathrm{PD}}=0.44 \pm 0.05 \mathrm{~s} / \mathrm{cm}\right)$ and low-loaded $\left(R_{\mathrm{O}_{2}}^{\mathrm{PD}}=0.45 \pm 0.05 \mathrm{~s} / \mathrm{cm}\right)$ cathodes at BOT. Therefore, the differences in $R_{\mathrm{O}_{2}}^{\text {total }}$ originate from a higher pressure independent transport resistance, due to their lower cathode $r f$ values $\left(R_{\mathrm{O}_{2}}^{\mathrm{PI}}\right.$ high-loaded: $0.29 \pm 0.04 \mathrm{~s} / \mathrm{cm} ; R_{\mathrm{O}_{2}}^{\mathrm{PI}}$ low-loaded: $0.37 \pm 0.05 \mathrm{~s} / \mathrm{cm}$ ).

Over the course of catalyst layer aging, the pressure dependent transport resistance remains reasonably constant, considering that the observed fluctuations are within the experimental accuracy. At the same time, $R_{\mathrm{O}_{2}}^{\mathrm{PI}}$ increases significantly. In general, $R_{\mathrm{O}_{2}}^{\mathrm{PI}}$ is composed of various contributions, namely Knudsen diffusion in small pores, diffusion in the ionomer and in water, as well as of the so-called $\mathrm{Pt}$ surface specific resistance $\left(R_{\mathrm{O}_{2}}^{\mathrm{Pt}}\right)$. Since the ionomer content and the overall electrode thickness was constant in all experiments, we ascribe the higher $R_{\mathrm{O}_{2}}^{\mathrm{PI}}$ of low-loaded electrodes to a $r f$ specific mass transport resistance. An increase of $R_{\mathrm{O}_{2}}^{\mathrm{PI}}$ was also observed by other researchers who conducted limiting current measurements for MEAs with different loading. ${ }^{9,10,37,55}$ In accordance with the ECSA trends presented in Figure 5, $R_{\mathrm{O}_{2}}^{\mathrm{PI}}$ increases with decreasing ECSA values in all aging protocols. Consistently, the highest transport resistances 
were obtained for procedures which showed the most severe ECSA losses, namely SW and TW-H for high-loaded cathodes as well as TW and SW for low-loaded cathodes. Comparing the transport resistance evolution for high-loaded catalyst layers, TW aging leads to less significant increases of $R_{\mathrm{O}_{2}}^{\mathrm{PI}}$ compared to SW and TW-H aging, which in turn show a similar transport resistance at each aging interval. Taking the similar ECSA decrease and the same performance in polarization curves of TW-H and SW into account, it is evident that the potential transient during aging is of minor importance, while the hold time at high potentials is the main contributor to electrode degradation. As described earlier, for degraded cathodes with ultra-low $r f$ values (low-loaded cathodes subjected to 30000 TW cycles or to $\geq 10000$ SW cycles), the deconvolution of pressure dependent and pressure independent resistance is not reliable, hence only the total transport resistance at $170 \mathrm{kPa}_{\mathrm{abs}}$ is shown in Figure 11.

To disentangle the effect of low $r f$ values on the observed increase of the total transport resistance from possible transport limitations originating from carbon corrosion, cathodes were exposed to a constant potential hold (CP) of $1.2 \mathrm{~V}_{\text {cell }}$ for $8 \mathrm{~h}$ at $95^{\circ} \mathrm{C}$ and $100 \% R H$. This procedure results in a thinning of the catalyst layer by approximately $40 \%$, while maintaining a reasonably high $r f$ value (from $222 \pm$ 10 at BOT to $90 \pm 2 \mathrm{~cm}_{\mathrm{Pt}}^{2} / \mathrm{cm}^{2}$ at EOT). Despite the fact that the catalyst layer structure collapses in this experiment, the total transport resistance increases only moderately from $0.70 \pm 0.01$ to $0.86 \pm$ $0.01 \mathrm{~s} / \mathrm{cm}$ (see Figure 11). On the one hand, the slight increase of the pressure independent resistance can be attributed to the loss of $E C S A$, comparable to the other testing procedures which lead to lower $r f$ values. On the other hand, since $R_{\mathrm{O}_{2}}^{\mathrm{PD}}$ is mostly associated with the transport resistances in the flow-field, the GDL, and the in the void volume within the catalyst layer, it would be reasonable to expect that it increases upon cathode thinning. Nevertheless, since the pressure dependent part of the transport resistance increases solely by $0.07 \pm$ $0.04 \mathrm{~s} / \mathrm{cm}$ (Figure 11), this hypothesis cannot be proven within the limited accuracy of this method. Considering that no thinning was observed for electrodes exposed to voltage cycling, the changes of $R_{\mathrm{O}_{2}}^{\text {total }}$, and especially $R_{\mathrm{O}_{2}}^{\mathrm{PI}}$ in the course of aging are clearly not attributed to carbon corrosion. In other words, the much larger increase of $R_{\mathrm{O}_{2}}^{\text {total }}$ and $R_{\mathrm{O}_{2}}^{\mathrm{PI}}$ over the course of all voltage cycling protocols (with the exception of the TW-LUPL protocol) where no cathode thinning was observed, must be related to phenomena other than carbon corrosion. Consistent with the essentially identical BOT and EOT performance of low-loaded cathodes subjected to TW-LUPL cycling, there is also essentially no increase of the total oxygen mass transport resistance.

As a comparison to the data in literature, ${ }^{9}$ the pressure independent part of the $\mathrm{O}_{2}$ mass transport resistance was plotted as a function of the $r f$ in Figure 12. The clear trend of strongly increasing $R_{\mathrm{O}_{2}}^{\mathrm{PI}}$ with decreasing platinum surface area (i.e., $r f<50 \mathrm{~cm}_{\mathrm{Pt}}^{2} / \mathrm{cm}^{2}$ ) presented here, was also observed by Greszler et al. and underlines the previously stated hypothesis that the high $\mathrm{O}_{2}$ mass transport resistance is a strong function of the cathode $r f$. The fact that aged, high-loaded electrodes show a similar $R_{\mathrm{O}_{2}}^{\mathrm{PI}}$ (e.g., after $30000 \mathrm{TW}$ cycles) compared to low-loaded cathodes at BOT further clarifies that the $r f$ is indeed a major influencing factor on the $\mathrm{O}_{2}$ mass transport. However, a disentanglement of $\mathrm{R}_{\mathrm{O}_{2}}^{\mathrm{PI}}$ into a fraction caused by the AST and another contribution, originating solely from the $r f$ of the cathode, cannot be drawn unambiguously with respect to the accuracy of the measurement.

Voltage loss analysis of aged cathodes.-Using the total oxygen mass transport resistance at BOT and EOT (Figure 11), the corresponding air polarization curves were corrected for all voltage loss contributions that are currently accessible by in situ measurement techniques, according to a preceding publication ${ }^{11}$ and are shown in Figure 13. In short, corrections of the potential include the HFR, the effective cathode proton conduction resistance, and the total oxygen mass transport resistance, while the current density was corrected

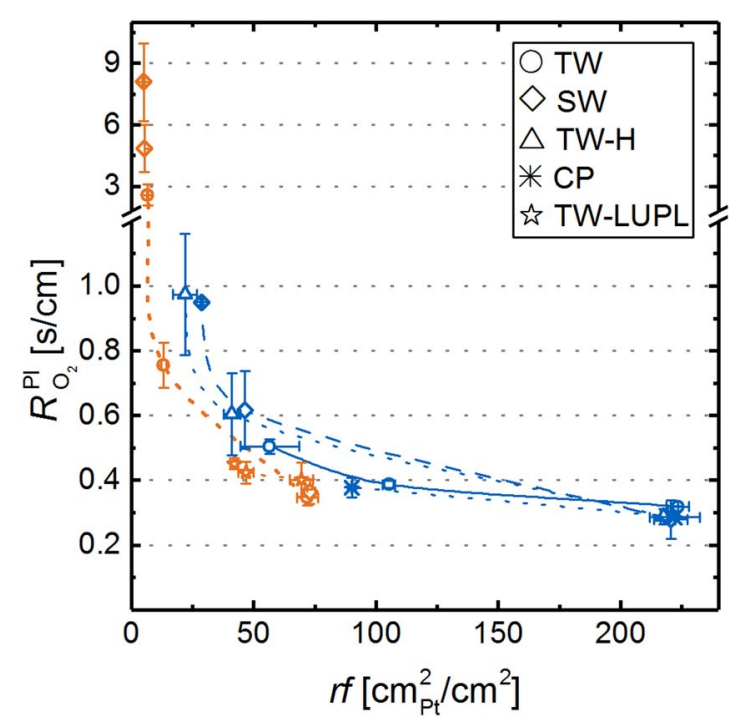

Figure 12. Pressure independent oxygen mass transport resistance, $R_{\mathrm{O}_{2}}^{\mathrm{PI}}$, as a function of the electrode's roughness factor, $r f$, for high-loaded (blue) and low-loaded (orange) MEAs at BOT and the respective aging intervals. If the EOT transport resistance could not be separated into pressure dependent and independent contributions (see open bars in Figure 11), the total transport resistance at $170 \mathrm{kPa}_{\mathrm{abs}}$ is given in this figure.

for $\mathrm{H}_{2}$ crossover, electrical short current and was normalized to the cathode's ECSA.

For BOT, all $\mathrm{H}_{2}$ /air polarization curves coincide with a Tafel slope of $\approx 73 \mathrm{mV} / \mathrm{dec}$ for high-loaded and $\approx 80 \mathrm{mV} / \mathrm{dec}$ for low-loaded catalyst layers. We attribute the higher Tafel slope in air compared to pure $\mathrm{O}_{2}$ to unaccounted mass transport limitations, which increase as the $\mathrm{O}_{2}$ concentration decreases. Upon aging, a strong deviation from the theoretical $70 \mathrm{mV} / \mathrm{dec}$ slope is observed at high current density, similar to the limitations observed in pure $\mathrm{O}_{2}$ (deviations from a straight $E_{\text {corrected }}$ vs $\log (i)$ line at EOT occur at $\approx 30 \mathrm{~mA} / \mathrm{cm}_{\mathrm{Pt}}^{2}$ for all aged cathodes, except for the low-loaded cathode subjected to SW cycling). However, the deviation from a straight $E_{\text {corrected }}$ vs $\log (i)$ line at EOT occurs earlier in air, viz., at $\approx 10 \mathrm{~mA} / \mathrm{cm}_{\mathrm{Pt}}^{2}$ (again, with the exception of the low-loaded cathode subjected to SW cycling, which deviates much earlier), which one would expect in case of significant oxygen transport resistances. The here observed deviation was also seen by other research groups at specific current densities ranging from $5-50 \mathrm{~mA} / \mathrm{cm}_{\mathrm{Pt}}^{2}$ in fully corrected air polarization curves with aged MEAs or at very low cathode $r f$ values, commonly attributed to a local oxygen diffusion resistance. ${ }^{9,10,12}$ Although a correction for the mass transport was applied to these measurements, it seems that the deviation at high Pt specific current density is not accounted for by the transport resistance determined by the limiting current method. Indeed, the conditions of the MEA during the limiting current measurement (local MEA temperature and $R H$ due to a high heat production rate at $<0.3 \mathrm{~V}$ ) are not identical to the operating conditions during the polarization curve (lower heat production rate at voltages of $\approx 0.6-0.5 \mathrm{~V}$ ) where the corrections are applied, which certainly introduces an error. Furthermore, due to changes in temperature or local $R H$, the utilization of the Pt surface area may change, increasing the oxygen flux to the remaining Pt surface or altering the ORR kinetics. ${ }^{59,67}$ While we cannot prove one or the other hypothesis, we consider the limitations of the oxygen mass transport determination method to be a probable cause of at least part of the observed deviations at high current density. However, whatever the origin of these unaccounted transport resistances may be, they clearly scale with the specific current density.

After full correction of the recorded $\mathrm{H}_{2}$ /air polarization curves for all known voltage loss contributions (namely the HFR, the effective cathode proton conduction resistance, and the total oxygen mass 


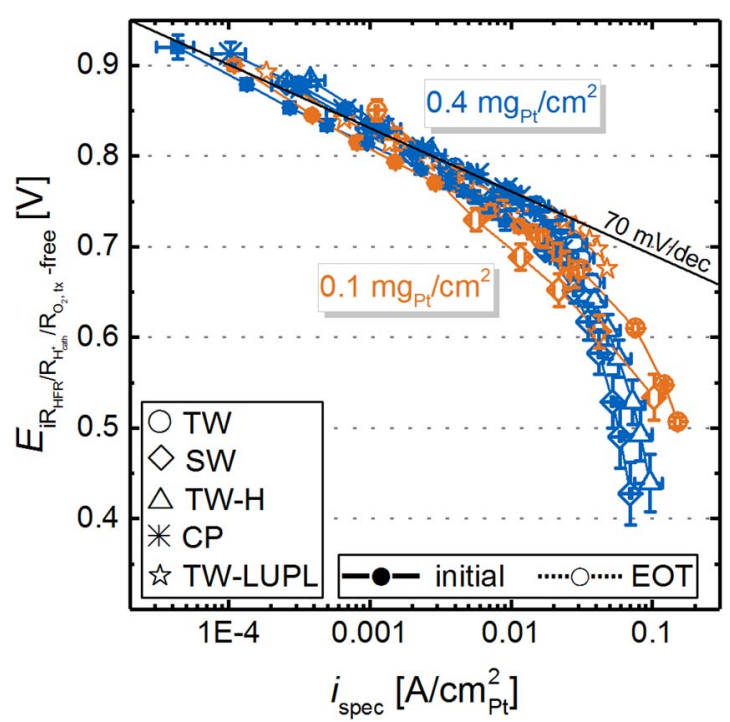

Figure 13. Transport-corrected differential flow $\mathrm{H}_{2}$ /air polarization curves at $80^{\circ} \mathrm{C}, 100 \% R H$, and $170 \mathrm{kPa}_{\mathrm{abs}}$ at BOT (full symbols) and EOT (open symbols) for high-loaded (blue) and low-loaded (orange) MEAs. The potential is corrected for the HFR, effective cathode proton conduction resistance, and the total oxygen mass transport resistance, while the current is corrected for the $\mathrm{H}_{2}$ crossover and ohmic shorting currents, and is normalized to the cathode $E C S A$. The two slanted lines indicate the specific current density region for high-loaded (blue) and low-loaded (orange) MEAs at BOT. BOT polarization curves of all tested MEAs were averaged and error bars symbolize the standard deviation over all MEAs. Error bars for EOT curves represent the mean absolute deviation between two measurements.

transport resistance), the $\mathrm{H}_{2}$ /air polarization curves can be compared to the theoretical, kinetically limited polarization curve, constructed from the experimentally determined ORR mass activities (see Figure 8a) and assuming simple Tafel kinetics with an intrinsic Tafel slope of $70 \mathrm{mV} /$ decade. The remaining unaccounted voltage losses are shown in Figure 14a for high-loaded and in Figure 14b for low-loaded catalyst layers at BOT (solid lines) and EOT for all aging protocols.

An analysis of Figure 14a reveals an almost quantitative account of all voltage losses for high-loaded MEAs at BOT (blue solid line), with only minor unaccounted losses at $2 \mathrm{~A} / \mathrm{cm}^{2}(15 \pm 11 \mathrm{mV})$. Upon catalyst layer aging over $30000 \mathrm{TW}$ cycles (open blue circles), the unaccounted voltage losses at higher current density $\left(>1 \mathrm{~A} / \mathrm{cm}^{2}\right)$ increase, pointing to the fact that not all voltage losses can be assessed by the current in situ diagnostic measurements. This discrepancy is even more pronounced for the MEAs exposed to SW and TW-H aging, where unaccounted voltage losses on the order of $250 \mathrm{mV}$ were observed at $2 \mathrm{~A} / \mathrm{cm}^{2}$. In accordance with the previously described evolution of the ECSA, the ORR mass activity, and the total oxygen mass transport resistance, both aging protocols (SW and TW-H) lead to identical unaccounted losses. In contrast, the corrosion of the carbon support (CP aging) does not lead to a significant increase of the unaccounted losses (e.g., $41 \pm 12 \mathrm{mV}$ at $2 \mathrm{~A} / \mathrm{cm}^{2}$ ) and therefore cannot explain the high, unaccounted voltage losses for SW and TW-H cycling.

The unaccounted voltage losses for low-loaded MEAs (Figure 14b) at BOT are slightly higher compared to high-loaded MEAs, and are in reasonably good agreement with our previous voltageloss analysis with the same catalyst. ${ }^{11}$ After aging by the TW or SW procedure, rather dramatic unaccounted voltage losses are already observed at low geometric current densities and become increasingly larger with current density. Considering the SW and TW-H aged, highloaded catalyst layers, the significant unaccounted voltage losses of all these measurements suggest that the quantitative evaluation of voltage loss contributions is impaired when using cathodes with low $r f$ values, i.e. at a high Pt specific current density. This hypothesis is further validated by the TW-LUPL voltage cycling test applied to the $0.1 \mathrm{mg}_{\mathrm{Pt}} / \mathrm{cm}^{2}$ cathodes: even after 30000 potential cycles, the unac-

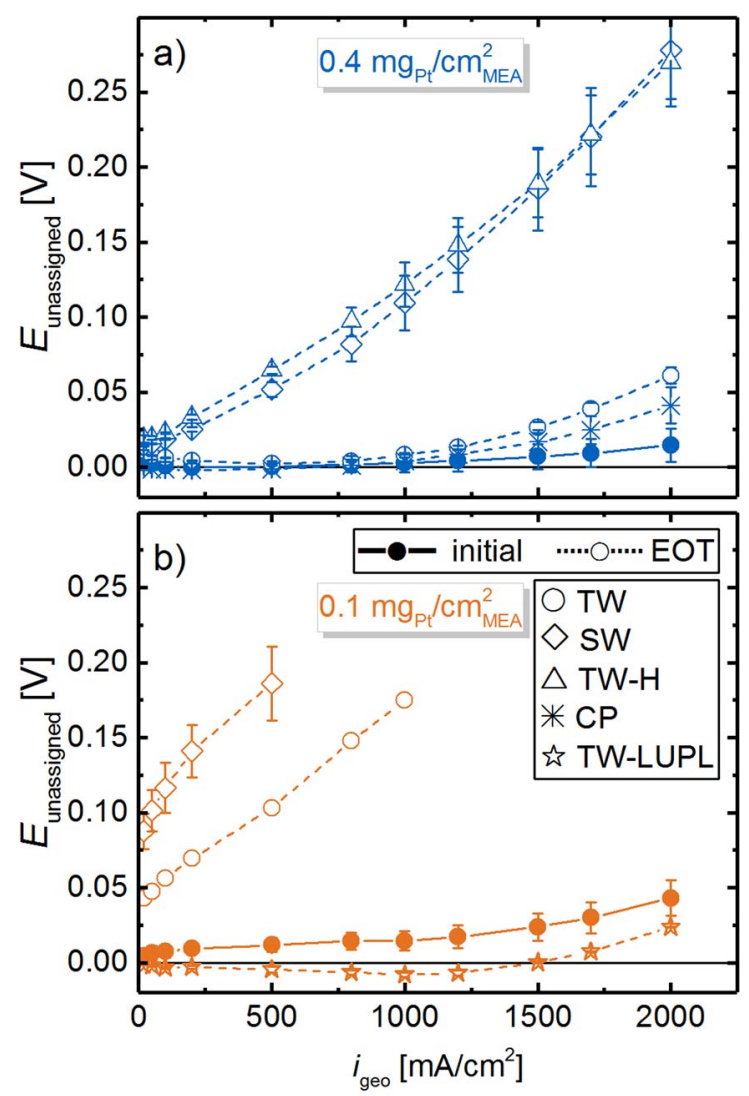

Figure 14. Unaccounted voltage losses between a theoretical, kinetically limited $\mathrm{H}_{2}$ /air polarization curve calculated from the measured ORR mass activity (assuming simple Tafel kinetics with an intrinsic Tafel slope of $70 \mathrm{mV} / \mathrm{dec}$ ) and polarization curves recorded in $\mathrm{H}_{2} /$ air (differential flow, $170 \mathrm{kPa}_{\mathrm{abs}}, 80^{\circ} \mathrm{C}$, and $100 \% R H$ ), where the potential is corrected for the $H F R$, effective cathode proton conduction resistance, and the total oxygen mass transport resistance for a) high-loaded and b) low-loaded cathode catalyst layers at BOT (full symbols) and EOT (open symbols).

counted voltage losses were substantially less compared to all other aging protocols, being as little as $24 \pm 1 \mathrm{mV}$ at $2 \mathrm{~A} / \mathrm{cm}^{2}$ at EOT, where the roughness factor is $42 \pm 2 \mathrm{~cm}_{\mathrm{Pt}}^{2} / \mathrm{cm}^{2}$. A very intriguing observation is that this roughness factor is only $\approx 2$-fold larger than the EOT roughness factor of the high-loaded cathodes subjected to SW cycling $\left(29 \pm 1 \mathrm{~cm}_{\mathrm{Pt}}^{2} / \mathrm{cm}^{2}\right)$, while the unaccounted voltage losses of the latter are $>250 \mathrm{mV}$ at $2 \mathrm{~A} / \mathrm{cm}^{2}$. Quite clearly, the currently available in situ diagnostics do not capture the critical voltage loss phenomena which must be related to the morphological changes with regards to Pt particle size and location within the electrode.

\section{Conclusions}

To better understand the influence of voltage cycling based ASTs on the development of mass transport resistances and on the extent to which they can be captured by currently available in situ diagnostics (ORR kinetics in $\mathrm{H}_{2} / \mathrm{O}_{2}$, cathode proton conduction resistance by impedance, oxygen transport resistance via limiting current measurements), we conducted a comprehensive voltage loss analysis on MEAs with high- and low-loaded cathodes $\left(0.4\right.$ and $\left.0.1 \mathrm{mg}_{\mathrm{Pt}} / \mathrm{cm}^{2}\right)$ over the course of ASTs based on different voltage cycling protocols. These include triangular wave (TW) and square wave (SW) cycles between 0.6 and $1.0 \mathrm{~V}_{\mathrm{RHE}}$, TW cycles between 0.6 and a lowered upper potential limit of $0.85 \mathrm{~V}_{\mathrm{RHE}}$ (TW-LUPL), as well as a combination of a triangular sweeps between 0.6 and $1.0 \mathrm{~V}_{\mathrm{RHE}}$, with potential hold periods at the upper and lower potential $(\mathrm{TW}-\mathrm{H})$, all conducted in $\mathrm{H}_{2} / \mathrm{N}_{2}$ (anode/cathode) at ambient pressure, $80^{\circ} \mathrm{C}$, and $100 \% R H$. 
A comparison of the ECSA and the $\mathrm{O}_{2}$ mass transport resistance evolution of MEAs aged by SW cycles leads to considerably faster degradation compared to TW cycles. To identify whether the fast potential transients or the potential hold phase is responsible for the faster degradation rates during SW aging, an additional procedure, consisting of a triangular potential scan followed by potential hold phase (TW-H) was tested. A comparison of the evolution of the cathode's ECSA, mass activity, and mass transport resistance revealed that the potential hold rather than the rate of the potential transient is the main contributor to cathode aging in voltage cycling ASTs, so that SW and $\mathrm{TW}-\mathrm{H}$ cycling profiles lead to identical aging rates with respect to the number of cycles.

For all ASTs, the magnitude of assignable and unassigned $\mathrm{O}_{2}$ mass transport resistances scaled predominantly with the cathode roughness factor, increasing with decreasing roughness factor, whereby the pressure dependent $\mathrm{O}_{2}$ transport resistance remained essentially constant. At the same time, ex situ cathode thickness measurements indicated the absence of cathode thinning and thus of significant carbon support corrosion. These results were further compared to an aging procedure which consisted of a constant potential hold at $1.2 \mathrm{~V}_{\text {cell }}$ for $8 \mathrm{~h}$ (at $95^{\circ} \mathrm{C}$ and $100 \% R H$ ), leading to significant carbon corrosion and concomitant cathode thinning, while maintaining a reasonably high cathode roughness factor. This analysis showed that the impact of carbon corrosion on the $\mathrm{O}_{2}$ mass transport resistance is minor compared to its increase with decreasing roughness factor.

While $30000 \mathrm{TW}$ or SW cycles between 0.6 and $1.0 \mathrm{~V}_{\mathrm{RHE}}$ dramatically decrease the $\mathrm{H}_{2}$ /air performance of low-loaded MEAs, it shows negligible degradation over 30000 cycles when a lowered upper potential limit of $0.85 \mathrm{~V}_{\mathrm{RHE}}$ is applied (TW-LUPL). This provides a guideline to limit cathode degradation under automotive conditions, namely by eliminating high potential periods (e.g., OCV).

\section{Acknowledgment}

The authors of this work would like to guide special thanks to Christoph Simon for insightful discussions about limiting current measurements and mass transport resistances. We would also like to thank Daniel Herein and Annett Reichl for fruitful discussions and valuable suggestions. Furthermore, the effort of Hany A. El-Sayed to acquire high quality TEM images is greatly appreciated.

\section{ORCID}

Gregor S. Harzer (D) https://orcid.org/0000-0002-1830-1931

Jan N. Schwämmlein (1) https://orcid.org/0000-0001-8902-4508

\section{References}

1. Toyota Motor Co. (accessed 05/18/2017), http://newsroom.toyota.co.jp/en/detail/ 4198334/.

2. Hyundai Motor Co. (accessed 05/18/2017), http://globalpr.hyundai. $\mathrm{com} / \mathrm{prCenter} /$ news/newsView.do?dID $=1581$.

3. Honda Motor Co., Ltd. (accessed 10/13/2017), http://hondanews.com/ honda-automobiles/channels/clarity-fuel-cell-press-releases/releases/southerncalifornia-customers-take-delivery-of-new-2017-honda-clarity-fuel-cell-sedan.

4. M. F. Mathias, R. Makharia, H. A. Gasteiger, J. J. Conley, T. J. Fuller, C. J. Gittleman, S. S. Kocha, D. P. Miller, C. K. Mittelsteadt, T. Xie, S. G. Yan, and P. T. Yu, Electrochem. Soc. Interface, 14, 24 (2005).

5. A. Veziroglu and R. Macario, Int. J. Hydrogen Energ., 36, 25 (2011)

6. H. A. Gasteiger, J. E. Panels, and S. G. Yan, J. Power Sources, 127, 162 (2004).

7. H. A. Gasteiger, S. S. Kocha, B. Sompalli, and F. T. Wagner, Appl. Catal., B., 56, 9 (2005).

8. A. Kongkanand and M. F. Mathias, J. Phys. Chem. Lett., 7, 1127 (2016).

9. T. A. Greszler, D. Caulk, and P. Sinha, J. Electrochem. Soc., 159, F831 (2012).

10. J. P. Owejan, J. E. Owejan, and W. Gu, J. Electrochem. Soc., 160, F824 (2013).

11. A. Orfanidi, P. Madkikar, H. A. El-Sayed, G. S. Harzer, T. Kratky, and H. A. Gasteiger, J. Electrochem. Soc., 164, F418 (2017).

12. P. Zihrul, I. Hartung, S. Kirsch, G. Huebner, F. Hasché, and H. A. Gasteiger, $J$. Electrochem. Soc., 163, F492 (2016).

13. C. H. Paik, G. S. Saloka, and G. W. Graham, Electrochem. Solid-State Lett., 10, B39 (2007).

14. R. Mukundan, G. James, J. Davey, D. Langlois, D. Torraco, W. Yoon, A. Z. Weber, and R. Borup, ECS Trans. 41, 613 (2011).
15. S. Jomori, N. Nonoyama, and T. Yoshida, J. Power Sources, 215, 18 (2012).

16. R. K. Ahluwalia, S. Arisetty, J.-K. Peng, R. Subbaraman, X. Wang, N. Kariuki, D. J. Myers, R. Mukundan, R. Borup, and O. Polevaya, J. Electrochem. Soc., 161, F291 (2014).

17. A. P. Young, J. Stumper, and E. Gyenge, J. Electrochem. Soc., 156, B913 (2009)

18. R. L. Borup, J. R. Davey, F. H. Garzon, D. L. Wood, and M. A. Inbody, J. Power Sources, 163, 76 (2006).

19. K. Yu, D. J. Groom, X. Wang, Z. Yang, M. Gummalla, S. C. Ball, D. J. Myers, and P. J. Ferreira, Chem. Mater, 26, 5540 (2014).

20. P. J. Ferreira, G. J. la O', Y. Shao-Horn, D. Morgan, R. Makharia, S. Kocha, and H. A. Gasteiger, J. Electrochem. Soc., 152, A2256 (2005).

21. S. Arisetty, X. Wang, R. K. Ahluwalia, R. Mukundan, R. Borup, J. Davey, D. Langlois, F. Gambini, O. Polevaya, and S. Blanchet, J. Electrochem. Soc., 159, B455 (2012)

22. R. G. Compton and G. H. W. Sanders, in Electrode potentials, Oxford University Press, Oxford, New York (1996).

23. J. P. Meyers and R. M. Darling, J. Electrochem. Soc., 153, A1432 (2006).

24. R. L. Borup, D. D. Papadias, R. Mukundan, D. Spernjak, D. A. Langlois, R. Ahluwalia, K. L. More, and S. Grot, ECS Trans. 69, 1029 (2015).

25. C. A. Reiser, L. Bregoli, T. W. Patterson, J. S. Yi, J. D. Yang, M. L. Perry, and T. D. Jarvi, Electrochem. Solid-State Lett., 8, A273 (2005).

26. Y. Yu, H. Li, H. Wang, X.-Z. Yuan, G. Wang, and M. Pan, J. Power Sources, 205, 10 (2012).

27. J. N. Schwämmlein, P. J. Rheinländer, Y. Chen, K. F. Freyer, and H. A. Gasteiger, ECS Trans. 80, 927 (2017).

28. C. Wagner, Z. Elektrochem. (Zeitschrift für Elektrochemie)., 65, 581 (1961).

29. R. M. Darling and J. P. Meyers, J. Electrochem. Soc., 150, A1523 (2003).

30. J. Zhang, B. A. Litteer, W. Gu, H. Liu, and H. A. Gasteiger, J. Electrochem. Soc., 154, B1006 (2007)

31. C. Simon, F. Hasché, D. Müller, and H. A. Gasteiger, ECS Trans. 69, 1293 (2015).

32. C. Simon, F. Hasché, and H. A. Gasteiger, J. Electrochem. Soc., 164, F591 (2017).

33. R. Makharia, M. F. Mathias, and D. R. Baker, J. Electrochem. Soc., 152, A970 (2005).

34. Y. Liu, M. W. Murphy, D. R. Baker, W. Gu, C. Ji, J. Jorne, and H. A. Gasteiger, J. Electrochem. Soc., 156, B970 (2009).

35. M. Eikerling and A. A. Kornyshev, J. Electroanal. Chem., 475, 107 (1999).

36. D. R. Baker, D. A. Caulk, K. C. Neyerlin, and M. W. Murphy, J. Electrochem. Soc., 156, B991 (2009).

37. N. Nonoyama, S. Okazaki, A. Z. Weber, Y. Ikogi, and T. Yoshida, J. Electrochem. Soc., 158, B416 (2011)

38. W. Gu, D. R. Baker, Y. Liu, and H. A. Gasteiger, in Handbook of Fuel Cells, $1^{\text {st }}$ ed., W. Vielstich, H. Yokokawa, and H. A. Gasteiger, p. 631, John Wiley \& Sons Ltd, Chichester (2009)

39. J. A. Gilbert, N. N. Kariuki, X. Wang, A. J. Kropf, K. Yu, D. J. Groom, P. J. Ferreira, D. Morgan, and D. J. Myers, Electrochimica Acta. 173, 223 (2015).

40. M. Uchimura and S. S. Kocha, ECS Trans. 11, 1215 (2007).

41. A. Ohma, T. Mashio, K. Sato, H. Iden, Y. Ono, K. Sakai, K. Akizuki, S. Takaichi, and K. Shinohara, Electrochim. Acta., 56, 10832 (2011).

42. R. N. Carter, S. S. Kocha, F. Wagner, M. Fay, and H. A. Gasteiger, ECS Trans. 11 403 (2007).

43. T. R. Garrick, T. E. Moylan, V. Yarlagadda, and A. Kongkanand, J. Electrochem. Soc., 164, F55 (2017).

44. T. J. Schmidt, H. A. Gasteiger, G. D. Stäb, P. M. Urban, D. M. Kolb, and R. J. Behm, J. Electrochem. Soc., 145, 2354 (1998).

45. A. López-Cudero, A. Cuesta, and C. Gutiérrez, J. Electroanal. Chem., 579, 1 (2005).

46. A. Cuesta, A. Couto, A. Rincón, M. C. Pérez, A. López-Cudero, and C. Gutiérrez, J. Electroanal. Chem., 586, 184 (2006).

47. A. López-Cudero, Á. Cuesta, and C. Gutiérrez, J. Electroanal. Chem., 586, 204 (2006).

48. D. Strmcnik, D. Tripkovic, D. van der Vliet, V. Stamenkovic, and N. M. Marković, Electrochem. Commun., 10, 1602 (2008).

49. F. T. Wagner, S. G. Yan, and P. T. Yu, in Handbook of Fuel Cells, $1^{\text {st }}$ ed., W. Vielstich, H. Yokokawa, and H. A. Gasteiger, p. 250, John Wiley \& Sons Ltd, Chichester (2009).

50. F. Mailard, S. Pronkin, and E. R. Savinova, in Handbook of Fuel Cells, 1st ed., W. Vielstich, H. Yokokawa, and H. A. Gasteiger, p. 101, John Wiley \& Sons Ltd, Chichester (2009).

51. J. A. Gilbert, N. N. Kariuki, R. Subbaraman, A. J. Kropf, M. C. Smith, E. F. Holby, D. Morgan, and D. J. Myers, J. Am. Chem. Soc., 134, 14823 (2012).

52. S. Cherevko, A. R. Zeradjanin, A. A. Topalov, N. Kulyk, I. Katsounaros, and K. J. J. Mayrhofer, Chem CatChem. 6, 2219 (2014).

53. H. A. Gasteiger, W. Gu, B. Litteer, R. Makharia, B. Brady, M. Budinski, E. Thompson, F. T. Wagner, S. G. Yan, and P. T. Yu, in Mini-Micro Fuel Cells, $1^{\text {st }}$ ed., S. Kakaç, A. Pramuanjaroenkij, and L. Vasiliev, p. 225, Springer Netherlands, Dordrecht (2008).

54. P. D. Beattie, V. I. Basura, and S. Holdcroft, J. Electroanal. Chem., 468, 180 (1999).

55. S. Shukla, D. Stanier, M. S. Saha, J. Stumper, and M. Secanell, J. Electrochem. Soc., 163, F677 (2016).

56. H. Liu, H. A. Gasteiger, A. Laconti, and J. Zhang, ECS Trans. 1, 283 (2006).

57. K. Kudo, T. Suzuki, and Y. Morimoto, ECS Trans. 33, 1495 (2010).

58. T. V. Reshetenko and J. St-Pierre, J. Electrochem. Soc., 161, F1089 (2014).

59. N. P. Subramanian, T. A. Greszler, J. Zhang, W. Gu, and R. Makharia, J. Electrochem. Soc., 159, B531 (2012)

60. S. S. Kocha, in Handbook of Fuel Cells, $1^{\text {st }}$ ed., W. Vielstich, A. Lamm, and H. A. Gasteiger, p. 538, John Wiley \& Sons Ltd, Chichester (2009). 
61. H. A. Gasteiger, W. Gu, R. Makharia, M. F. Mathias, and B. Sompalli, in Handbook of Fuel Cells, $1^{\text {st }}$ ed., W. Vielstich, A. Lamm, and H. A. Gasteiger, p. 593, John Wiley \& Sons Ltd, Chichester (2009).

62. S. Zhang, X.-Z. Yuan, J. N. C. Hin, H. Wang, K. A. Friedrich, and M. Schulze, J. Power Sources, 194, 588 (2009).

63. K. Kinoshita, J. Electrochem. Soc., 137, 845 (1990).
64. K. J. J. Mayrhofer, D. Strmenik, B. B. Blizanac, V. Stamenkovic, M. Arenz, and N. M. Marković, Electrochim. Acta., 53, 3181 (2008).

65. C. Simon, D. Kartouzian, D. Müller, F. Wilhelm, and H. A. Gasteiger, J. Electrochem. Soc., 164, F1697 (2017).

66. D. A. Caulk and D. R. Baker, J. Electrochem. Soc., 157, B1237 (2010),

67. K. Shinozaki, H. Yamada, and Y. Morimoto, J. Electrochem. Soc., 158, B467 (2011). 